\title{
Networks versus vertical integration
}

\author{
Rachel E. Kranton* \\ and \\ Deborah F. Minehart**
}

We construct a theory to compare vertically integrated firms to networks of manufacturers and suppliers. Vertically integrated firms make their own specialized inputs. In networks, manufacturers procure specialized inputs from suppliers that, in turn, sell to several manufacturers. The analysis shows that networks can yield greater social welfare when manufacturers experience large idiosyncratic demand shocks. Individual firms may also have the incentive to form networks, despite the lack of long-term contracts. The analysis is supported by existing evidence and provides predictions as to the shape of different industries.

\section{Introduction}

- Supply relations vary across industries. Case studies show an abundance of industries organized as networks: manufacturers procure specialized inputs from suppliers that, in turn, sell to several other manufacturers. Little economic theory, however, considers this industrial form. ${ }^{1}$ This article studies networks and vertical integration as alternative supply structures for specialized inputs. We consider the relationship between industrial structure, demand uncertainty, and investment costs. We show that networks may be related to high levels of idiosyncratic shocks facing manufacturers. The analysis is supported by existing evidence and provides predictions as to the shape of different industries.

Networks (we provide examples below) are distinct from vertically integrated firms and anonymous markets. In a market, where manufacturers and suppliers have no

* University of Maryland; kranton@econ.umd.edu.

** Boston University; minehart@bu.edu.

We are grateful to Sanjeev Goyal, Stefan Krieger, Michael Riordan, and especially the Editor, Glenn Ellison, and two anonymous referees for comments and suggestions. Rachel Kranton thanks the Russell Sage Foundation for its hospitality and financial support as well as the NSF (grant no. SBR-9806063). Deborah Minehart thanks the NSF (grant no. SBR-9806201) for financial support and the Cowles Foundation, Yale University, for hospitality and financial support.

${ }^{1}$ See Holmström and Roberts (1998) for a survey. Helper and Levine (1992) consider networks where a buyer has a single supplier for each input. Grossman and Helpman (1999) consider matching markets for specialized inputs. Network models of particular industries include airlines (Hendricks, Piccione, and Tan, 1995), communications (Economides and Himmelberg, 1995; Henriet and Moulin, 1996), and energy (Smith, Backerman, and Rassenti, 1996). Formal theory of networks includes Myerson (1977), Jackson and Wolinksy (1996), Bala and Goyal (forthcoming), and Kranton and Minehart (forthcoming (a)). 
relationships, only standardized inputs can be produced. On the other side of the spectrum, a vertically integrated manufacturer obtains specialized inputs from its own plants. General Motors in the 1950s is the canonical example. In networks, external suppliers provide specialized inputs. Manufacturers maintain ongoing contacts with these suppliers; they train them, provide equipment and know-how, and otherwise invest in the relationship. Suppliers also invest in assets that allow them to produce inputs to buyers' specifications. Typically, manufacturer-supplier relationships are not exclusive; buyers have several suppliers for each input, and suppliers have several clients.

This article constructs a theory to compare vertically integrated firms to networks of manufacturers and suppliers. We consider manufacturers' "make or buy" decisions. A manufacturer can invest in links to external sellers from which it will buy specialized inputs. When many firms do this, a network is formed. A manufacturer can, alternatively, vertically integrate and build a dedicated asset to make its own inputs. These dedicated assets are cheaper than flexible assets used by external sellers to produce for different buyers.

We argue that a social benefit of flexible assets and networks derives from uncertainty in demand for specialized inputs. ${ }^{2}$ A simple example illustrates. Consider an industry of designer clothing consisting of $N>2$ manufacturers, each with its own "style." In each season, only two of the $N$ are fashion "winners" and secure half of the consumer demand each. ${ }^{3}$ Normalize this demand to two, and suppose that each potential supplier can invest in one unit of flexible costly capacity. An efficient industrial structure then involves exactly two suppliers that sell to whichever manufacturers are the fashion "winners." The firms may be thought of as a network-given that each manufacturer has invested in the suppliers, by training them, loaning equipment, explaining designs, etc. ${ }^{4}$ The suppliers are flexible because, thanks to their own and the manufacturers' investments, they can produce for any of them.

We discuss below two cases, the garment industry in New York City and the Japanese electronics industry, where manufacturers have uncertain demand for specialized inputs and the industries are organized as networks. In both settings, a link between a buyer and seller allows the seller to make specialized inputs to the buyer's specifications. We also discuss industries whose structures have changed over time and different sources of demand uncertainty.

Our theory first establishes a connection between industrial structure and uncertainty in demand. Manufacturers in our model face idiosyncratic shocks to their demands for inputs. The relationship between such uncertainty and economies of scale has its origins in the "repairman problem" (Feller, 1950; Rothschild and Werden, 1979). We add the requirement of links between trading partners. These links allow a supplier to produce a specialized input for a buyer. We show how the position of a link determines its contribution to economic welfare, and we relate that contribution to the distribution of buyers' idiosyncratic shocks. We determine the efficient industrial structure, showing when networks yield greater welfare than vertical integration.

We then ask whether firms, acting noncooperatively and in their own self-interests, will form efficient industrial structures. In a two-stage game, each manufacturer either builds its own supply facility (i.e., vertically integrates) or invests in links to external

${ }^{2}$ Other advantages of networks put forward in the case study literature include technological diffusion, information sharing, and economies of scope.

${ }^{3}$ In our model, the uncertainty in buyers' valuations is identically and independently distributed, not perfectly correlated as in this example. However, the economic intuition and results are qualitatively the same.

${ }^{4}$ Uzzi (1996) discusses the many facets of the information transfer from garment manufacturers to their suppliers. This transfer assures that a supplier will produce inputs according to the buyer's style.

O RAND 2000. 
suppliers. Each supplier decides whether or not to invest in flexible productive capacity. Demand shocks are then realized, and production and exchange takes place.

This model implicitly assumes that long-term contracting for investment and future pricing is not possible. There is the possibility of "holdup" in networks, where ex ante investments affect ex post bargaining positions. There is no such problem in a vertically integrated firm. We find that vertical integrated structures are always equilibrium outcomes when they are efficient. The existence of network equilibria is a more complicated problem, since individual investment incentives depend on how a pattern of links translates into payoffs for different firms.

We consider two possible solutions to ex post allocation of surplus in networks: (i) a cooperative solution where firms earn their Shapley values as payoffs, and (ii) firms earn competitive payoffs that reflect supply and demand for inputs. We find that competitive payoffs better align investment incentives with economic welfare, though not perfectly. However, despite suboptimal investment, equilibrium network industrial structures are often "second best." As buyers face greater demand uncertainty, networks are equilibrium outcomes and yield greater welfare than vertical integration.

A series of earlier articles has considered the impact of demand uncertainty on firm behavior and industry structure. In this work, firms must set prices or quantities before demand uncertainty is resolved (Baron, 1971; Leland, 1972; Holthausen, 1976; Carlton, 1978). Carlton (1979) shows that when sellers cannot adjust their prices to the number of buyers, vertical integration is never efficient. Buyers vertically integrate to avoid input rationing, but demand variation increases when buyers withdraw from the market. In the present article, we consider different reasons for vertical integration. Here (as in Bolton and Whinston (1993)), there is no input rationing, since prices adjust after uncertainty is realized. Under some demand and cost conditions, vertical integration is the efficient industrial structure. When it is not, firms may still have the incentive to vertically integrate because of incomplete contracting. Overall, in our setting there is a tension, in terms of both social welfare and individual profits, between vertical integration and disintegration.

Our theory helps clarify the benefits of network industrial structures by distinguishing between firm-specific and aggregate uncertainty. Piore and Sabel's (1984) influential work on "flexible specialists" argues that networks emerge in times of greater economic uncertainty, and in case studies of networks, demand fluctuations figure prominently. Our results indicate that uncertainty, per se, does not lead to networks. Idiosyncratic shocks, not aggregate shocks, are the source of network benefits. If, however, firms face greater idiosyncratic shocks during recessions, ${ }^{5}$ then industrial structure could become more "network-like" during business slowdowns. ${ }^{6}$

The next section discusses industry examples. Section 3 presents the basic model of demand uncertainty, investments, vertical integration, and networks. Section 4 determines when different industrial structures yield the greatest social welfare. Section 5 examines the strategic incentives of firms to vertically integrate or invest in a network. Section 6 discusses extensions of the model. Section 7 concludes.

\section{Examples}

- Our first network example is the Women's Better Dress sector of the garment industry in New York City (Uzzi, 1996, 1997). Manufacturers (also known as jobbers)

${ }^{5} \mathrm{~A}$ number of economic series are known to be more uncertain during recessions (Schwert, 1989), suggesting that firm-specific uncertainty might also be greater.

${ }^{6}$ Lilien (1982) argues that the movement of labor out of declining industries causes unemployment in recessions. By analogy, flexible suppliers should fare better during recessions than suppliers dedicated to a particular firm or industry. 
design and market garments, hiring contractors to fabricate them. The manufacturers and contractors are linked by long-term, ongoing relationships. These links embody "fine-grained information" acquired over time about a manufacturer's particular style. A contractor needs this information to make a garment correctly. For example, there are many different properties of fabrics, how they "fall," "run," "stretch," or "forgive stitching," to which production procedures must be subtly adjusted. The necessary adjustments are impossible to specify in advance. ${ }^{7}$ Suppliers with experience in making such adjustments can allow the manufacturer to take advantage of rapidly changing market conditions.

The market for Better Dresses is highly fashion-sensitive. Firms face significant idiosyncratic demand uncertainty. Some designs succeed, others fail. When a manufacturer's design is "hot," it has a surge in orders. The manufacturer must then be able to locate an experienced contractor on short notice (that is, links must be established ex ante). To help insure production, manufacturers often have long-term relationships with multiple sellers. Conversely, to protect themselves against the difficulties of any one manufacturer, sellers have long-term relationships with multiple manufacturers. ${ }^{8}$ Manufacturers often spread their work among their contractors to cushion them against demand uncertainty. ${ }^{9}$ Uzzi (1996) finds that contractors with long-term ongoing relationships with several manufacturers have a lower failure rate than those that primarily engage in arm's-length transactions with many manufacturers. The value of their output is higher, and they have a more reliable stream of orders.

Our second example is the electronics industry in Japan. Here, Nishiguchi (1994) describes vertical supply networks for finished products (as opposed to components), where long-term specific investments, i.e., links, are important. Assemblers need "customer-specific knowledge," training, tools, and machines that have little use in assembly for other manufacturers. Relationships between manufacturers and contractors develop over many years, with contractors only gradually taking the complex assignment of finished product assembly. ${ }^{10}$ This slow qualification process is sometimes formalized as a grading system in which manufacturers score the subcontractors' performance. Subcontractors are given high-level work only after they have performed well in low-level tasks. ${ }^{11}$

Assemblers work for several manufacturers to protect themselves from demand uncertainty and indeed may be encouraged to do this by their clients. ${ }^{12}$ As in the garment industry, firms have multiple links. ${ }^{13}$ Links to a few manufacturers in different

${ }^{7}$ A manufacturer relates: "If we have a factory that is used to making our stuff, they know how it's supposed to look. ... They will know how to work the fabric to make it look the way we intended. A factory that is new will just go ahead and make it. They won't know any better" (Uzzi, 1996, p. 678).

${ }^{8}$ Over a sixteen-month period in 1990-1991, 25\% of manufacturers hired 5 or fewer contractors, $30 \%$ hired 5-12 contractors, and 40\% hired 20 or more contractors. As for contractors, $35 \%$ sold to 3 or fewer manufacturers, $45 \%$ sold to 4-8 manufacturers, and $20 \%$ sold to 9 or more manufacturers (Uzzi, 1996).

${ }^{9}$ A manufacturer relates, "[w]here we put work all depends on the factory. If it's very busy [with another manufacturer's orders] I'll go to another factory that needs the work to get by in the short run" (Uzzi, 1997, p. 54).

${ }^{10}$ At Fuji Electric in 1983, 25\% of its subcontractors had done business with Fuji for 21 years or more. For 63\%, the business relationship had lasted at least 6 years (Nishiguchi, 1994).

${ }^{11}$ Nishiguchi (1994).

${ }^{12}$ Nishiguchi relates: "During recession, it became general practice for the large customers ... to help those subcontractors most likely to be severely affected to change their products and look elsewhere for business"' (p. 118),

${ }^{13}$ First tier electronics assembly contractors had on average 3.36 regular customers who each placed orders several times over the period of a year. 
lines of business help to protect a contractor against drops in demand in any one of them.

More generally, demand uncertainty characterizes many industries with network supply structures. We can divide industry case studies into two broad categories. The first is fashion, culture, and craft industries such as garments, textiles, shoes, leather goods, and toys. ${ }^{14}$ In these industries, volatile consumer preferences underlie uncertainty in a manufacturer's demand for inputs. The second category is high-tech industries such as electronics, engineering, computers, semiconductors, custom machinery, and automobile parts. ${ }^{15}$ In these industries, uncertainty over firms' success in innovation and demand for new products both translate into idiosyncratic uncertainty in input demands.

We now turn to a formal model that explores the connection between input demand uncertainty, investment in links between firms, and industrial structure.

\section{The basic model: technology and industrial structure}

- There are $\bar{B} \geq 2$ buyers, each of which demands one (indivisible) unit of a specialized input, that is, an input made to its specifications. ${ }^{16}$ Each buyer $i$ has a random valuation for such an input, $\tilde{v}_{i}=\tilde{z}+\tilde{\epsilon}_{i}$, where $\tilde{z}$ is an aggregate shock and $\tilde{\epsilon}_{i}$ is an idiosyncratic shock. We assume that for all possible realizations $z$ and $\epsilon_{i}$ of $\tilde{z}$ and $\tilde{\epsilon}_{i}$, $z>0$ and $v_{i}=z+\epsilon_{i} \geq 0 .{ }^{17}$ The shocks $\tilde{\epsilon}_{i}$ are identically and independently distributed with distribution $G_{\sigma}(\epsilon) \equiv F(\epsilon / \sigma)$, where $\sigma \geq 0$ is a parameter and $F$ is a continuous distribution with mean zero. Intuitively, the parameter $\sigma$ stretches the distribution of $\tilde{\epsilon}_{i}$, leaving the mean at zero. ${ }^{18}$ We will conduct comparative statics on $\sigma$ and call it the dispersion of buyers' idiosyncratic shocks. Let $\mu^{n: B}(\sigma)$ denote the expectation of the $n$ th-highest realization of the idiosyncratic shocks of $B$ buyers; that is, $\mu^{n: B}(\sigma)$ is the $n$ th-order statistic of $B$ draws from a distribution $G_{\sigma}$. Given our assumptions, $\mu^{n: B}(\sigma)$ is homogeneous of degree one in $\sigma .^{19}$ The expectation of the $n$ th-highest valuation of $B$ buyers is then $\bar{z}+\sigma \mu^{n: B}(1)$, where $\bar{z}$ is the mean of $\tilde{z}$. We do not specify further the distribution of the aggregate shock, as only the mean affects outcomes in the model.

Specialized inputs can be produced using either dedicated or flexible assets. A dedicated asset can be used to produce one input for only one buyer; a flexible asset can be used to produce one input for one of several buyers.

$\square \quad$ Buyer production of specialized inputs. A buyer can produce a specialized input for itself by investing in a dedicated asset; i.e., building its own productive facility. The investment cost is $\alpha_{d}$. The asset provides a unit of productive capacity that can be

${ }^{14}$ Lazerson (1993) and Brusco (1982) study the garment industry in Emilia-Romagna, Italy. Cawthorne (1995) studies cotton knitwear in Tiruppur, India. Schmitz (1995) analyzes a shoe manufacturing network in the Sinos Valley, Brazil. Rabellotti (1995) compares Italian and Mexican shoe-manufacturing networks. "The Puppet-master of Toytown," Economist, September 6, 1997, p. 88, discusses the toy industry.

${ }^{15}$ Saxenian (1994) studies Silicon Valley and Route 128. Nohria (1992) also studies Route 128. Scott (1987) analyzes defense subcontracting in Orange County, California. Lorenz (1989) studies engineering and electronics industries in France. Nishiguchi (1994) studies Britain as well as Japan. We discuss the automobile industry below. Scott, Nishiguchi, and Lorenz all consider NC (numerically controlled) machine tools. Piore and Sabel (1984) also discuss NC tools in Japan.

${ }^{16}$ We discuss below how the results extend to multiple unit demand.

${ }^{17} \mathrm{We}$ are assuming that the distribution of $\tilde{\epsilon}_{i}$ is independent of the distribution of the aggregate shock, $z$. Further specifications of the model could incorporate correlation between the two shocks or other relationship between their distributions.

${ }^{18}$ For $\tilde{\sigma}>\sigma$, the distribution $G_{\tilde{\sigma}}(\epsilon)$ is a mean-preserving spread of $G_{\sigma}(\epsilon)$.

${ }^{19}$ The expectation of the $n$ th-order statistic of $G_{\sigma}(\epsilon)$ is $\mu^{n: B}(\sigma)=\int_{-\infty}^{\infty}\left[G_{\sigma}(\epsilon)\right]^{B-n}\left[1-G_{\sigma}(\epsilon)\right]^{n-1} \epsilon d G_{\sigma}(\epsilon)$. It follows easily from this formula that $\mu^{n: B}(\sigma)$ is homogeneous of degree one in $\sigma$. 
used to produce one (indivisible) unit of specialized input at zero marginal cost. We call a buyer that builds a dedicated asset a vertically integrated firm.

$\square \quad$ Network production of specialized inputs. $\bar{S}$ specialized sellers can each potentially produce one (indivisible) unit of input. For a seller to produce a specialized input for a buyer, the buyer must invest in a "link" to the seller, incurring a cost $c$. The seller must also invest in a flexible asset that allows it to produce one specialized input for any linked buyer. This asset costs $\alpha_{f}$, where $\alpha_{f}+c \geq \alpha_{d}$. The combination of flexible capacity and links to specific buyers makes a seller a "flexible specialist"; i.e., it can produce a specialized input for one of several different buyers. Sellers that invest in productive capacity and their linked buyers are called a network of firms.

Notice that networks involve both specific investments and quasi-specific investments. The link between a buyer and seller is a specific investment, since it has no value to any other firm. A seller's productive asset is quasi-specific, since it can have value to more than one buyer but its value is limited. The asset has no value to any buyer to which the seller is not linked.

Notice also that the distinction between vertical integration and networks involves both ownership of the asset and the type of asset. For most of the analysis, we assume only sellers can own flexible assets and only buyers (as vertically integrated firms) can own dedicated assets. This definition of vertical integration is stronger than others in the literature, where vertical integration is based only on ownership (Grossman and Hart, 1986; Hart and Moore, 1990). In the present article, a vertically integrated firm involves a dedicated asset and is therefore a self-contained production chain; it neither buys nor sells inputs. This assumption allows us to focus on a manufacturer's "make or buy" decision without the further complication of a "make and sell" decision on inputs. It is motivated by the case studies of network production where flexible assets are owned by external suppliers. Later, in Section 6, we explore the possibility that buyers can own flexible assets and can, therefore, produce specialized inputs for themselves and other buyers. We call this structure vertical merger to distinguish it from vertical integration as defined above.

$\square \quad$ Standard inputs. Buyers can also forgo purchase of specialized inputs and make no investments whatsoever. We assume that there is a competitive fringe of sellers (different from the sellers enumerated above) that produce standard inputs. We normalize the value of these inputs to zero and normalize all production costs to zero. This option guarantees buyers at least a zero payoff. The valuations $v_{i}$ can now be interpreted as the incremental value of specialized inputs over standard inputs and the investment costs $\alpha$ and $c$ as incremental costs.

Industrial structure. The investments of the $\bar{B}$ buyers and $\bar{S}$ specialized sellers form an industrial structure. Firms are divided into networks, vertical integration, and noninvestors. ${ }^{20}$ We represent an industrial structure as a graph, $G \cdot{ }^{21}$ Figure 1 shows an industrial structure for four buyers and one specialized seller. Buyers 1 and 2 are in a network with seller 1 , which has invested in a flexible productive asset, as indicated by the box. Buyers 3 and 4 have invested in dedicated assets, also indicated by boxes, and are vertically integrated firms.

${ }^{20}$ We can divide firms in this way because (i) it will never be efficient for a buyer to have both a link and a dedicated asset and (ii) no buyer will ever have an incentive to make both types of investments.

${ }^{21}$ Kranton and Minehart (forthcoming (a)) develop a model of networks as graphs. We refer the reader to that article for technical exposition of the network model. 


\section{FIGURE 1}

INDUSTRIAL STRUCTURE WITH A NETWORK AND TWO VERTICALLY INTEGRATED FIRMS
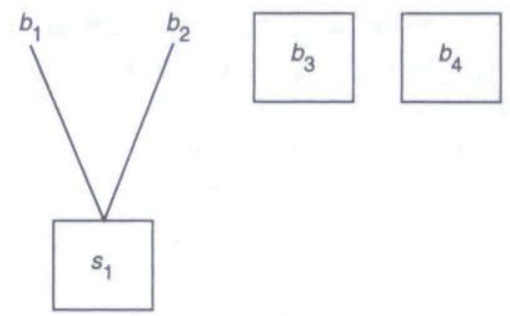

Timing. We assume that any investments must be made before demand uncertainty is resolved. That is, firms invest in anticipation of future, short-term, demand for inputs. This assumption captures aforementioned observations of "real-world" industrial settings where firms must respond rapidly to changing demand.

\section{Economic welfare and efficient industrial structures}

- In this section we compare the welfare generated by different industrial structures and characterize efficient industrial structures. Since investments are made before uncertainty is resolved, we evaluate welfare from an ex ante perspectivethe difference between the ex ante investment costs and expected ex post gains from trade. In our welfare analysis we assume that, given an industrial structure, ex post trade is efficient, i.e., the highest possible gains from trade are realized. We make this assumption both as a benchmark and because any bargaining process with sufficiently small renegotiation costs should yield an efficient allocation. ${ }^{22}$

For an industrial structure $\mathcal{G}$, we first describe the maximal expected ex post gains from trade. Let $\mathbf{v}=\left(v_{1}, \ldots, v_{\bar{B}}\right)$ be a vector of buyers' realized valuations, and let $A$ be an allocation of goods. ${ }^{23}$ The economic surplus associated with an allocation $A$ is the sum of the valuations of the buyers that secure specialized inputs in $A$. We denote this surplus $w(\mathbf{v}, A) .{ }^{24}$ For a given $\mathbf{v}$ and industrial structure $G$, an allocation $A$ is efficient if and only if there does not exist another feasible allocation that yields greater surplus. The word "feasible" is important. Every vertically integrated buyer can always obtain a good. But in a network, the pattern of links will constrain which buyers can obtain goods from which sellers. Let $A^{*}(\mathbf{v}, \mathcal{G})$ denote an efficient allocation. ${ }^{25}$ With $A^{*}(\mathbf{v}, \mathcal{G})$ for each ordering of buyers' valuations, we can determine the maximal expected ex post gains from trade for a given industrial structure: $E_{\mathbf{v}}\left[w\left[\mathbf{v}, A^{*}(\mathbf{v}, G)\right]\right]$, where the expectation is taken over all the possible realizations of buyers' valuations.

${ }^{22}$ This assumption contrasts with Carlton (1978), Carlton (1979), and other articles cited above where prices do not adjust after uncertainty is realized. In an industrial setting with a few buyers and sellers, we would expect prices to adjust to demand conditions. Indeed, as we assume below, with sufficiently small renegotiation costs, prices should be pairwise stable. That is, no linked buyer and seller can strike a deal that makes them both better off.

${ }^{23}$ See Kranton and Minehart (forthcoming (a)) for formal notation. In Figure 1, an example of an allocation is: buyer 1 procures an input from seller 1 , buyer 2 does not procure an input, and buyers 3 and 4 each procure an input internally. Call this allocation $\tilde{A}$.

${ }^{24}$ For the allocation $\tilde{A}, w(\mathbf{v}, \tilde{A})=v_{1}+v_{3}+v_{4}$.

${ }^{25}$ The allocation $\tilde{A}$ is efficient if and only if $v_{1} \geq v_{2}$. 


\section{FIGURE 2}

TWO NETWORK STRUCTURES WITH FOUR BUYERS AND TWO SELLERS
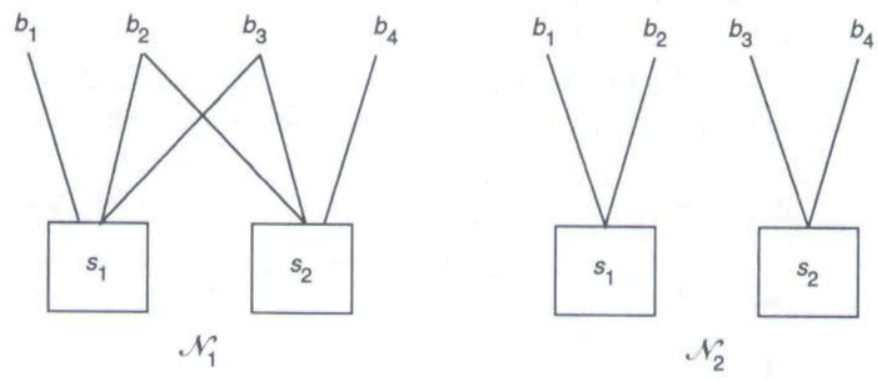

The welfare generated by an industrial structure, $W(G)$, is the maximal expected ex post gains from trade minus total investment costs:

$$
W(\mathcal{G}) \equiv E_{\mathbf{v}}\left[w\left(\mathbf{v}, A^{*}(\mathbf{v}, \mathcal{G})\right)\right]-\alpha_{d} \sum_{i=1}^{\bar{B}} \delta_{i}(\mathcal{G})-c \sum_{i=1}^{\bar{B}} \ell_{i}(\mathcal{G})-\alpha_{f} \sum_{j=1}^{\bar{S}} \kappa_{j}(\mathcal{G})
$$

where $\delta_{i}(G)=1$ when buyer $i$ is a vertically integrated firm and equals 0 otherwise, $\ell_{i}(G)$ is the number of buyer $i$ 's links, and $\kappa_{j}(G)=1$ when seller $j$ has invested in productive capacity and equals 0 otherwise. An industrial structure $G$ is efficient if and only if there does not exist another structure $\mathcal{G}^{\prime}$ such that $W\left(\mathcal{G}^{\prime}\right)>W(\mathcal{G})$. That is, efficient industrial structures balance ex post expected gains from trade and ex ante investment costs. In our analysis of efficient structures below, we will assume that $\alpha_{d}=\alpha_{f}=\alpha$. This assumption simplifies the presentation, and the implications of a divergence in these costs $\left(\alpha_{d}<\alpha_{f}\right)$ are easy to see.

We next characterize efficient industrial structures. A structure where all buyers build dedicated assets we call a vertically integrated structure. A structure where no buyers make any investments is called a no-investment structure. A network industrial structure is any structure that contains at least one network, that is, there is at least one buyer that has a link to at least one seller that has a flexible asset. Other buyers in a network structure may be vertically integrated or not investing.

All propositions in the article apply to an industry with an arbitrary number of buyers $\bar{B}$ and sellers $\bar{S}$.

We illustrate our general results with a four-buyer-industry example. We compare the following simple structures: a vertically integrated structure, which we denote $\mathcal{V}$, a no-investment structure, $X$, and two network structures where all four buyers are in networks and two sellers invest in flexible assets. Figure 2 illustrates the two networks with four buyers and two sellers. ${ }^{26}$ The Appendix expands this example to all possible industrial structures for four buyers. ${ }^{27}$ For all four buyers as vertically integrated firms, we have $W(\mathcal{V})=4[\bar{z}-\alpha]$. We simply have $W(X)=0$.

To calculate network welfare, we determine the efficient allocation for each possible ordering of buyers' valuations. In $\mathcal{N}_{1}$, suppose that buyer's shocks are realized in

${ }^{26}$ We choose these networks for our example because in the class of four-buyer-two-seller networks they yield the highest welfare, as discussed in the Appendix.

${ }^{27}$ The full comparison considers structures where some buyers are in networks and others are either vertically integrated or not investing. We do not consider nonnetwork structures where some buyers vertically integrate and the other buyers do not invest because either $\mathcal{V}$ or $X$ always yields weakly higher welfare. 
the following order: $\epsilon_{1}>\epsilon_{2}>\epsilon_{3}>\epsilon_{4}$. In the efficient allocation for this ordering, $b_{1}$ obtains a good from $s_{1}$ and $b_{2}$ obtains a good from $s_{2}$. Indeed, in $\mathcal{N}_{1}$ for any ordering of buyers' valuations, the buyers with the two highest valuations obtain inputs. ${ }^{28}$ Thus $W\left(\mathcal{N}_{1}\right)=2 \bar{z}+\mu^{1: 4}(\sigma)+\mu^{2: 4}(\sigma)-6 c-2 \alpha$. To calculate $W\left(\mathcal{N}_{2}\right)$, suppose again that $\epsilon_{1}>\epsilon_{2}>\epsilon_{3}>\epsilon_{4}$. In $\mathcal{N}_{2}$ it is not possible for both buyers 1 and 2 to obtain inputs. In the efficient allocation, $b_{1}$ obtains a good from $s_{1}$ and $b_{3}$ obtains a good from $s_{2}$. For every ordering of buyers' valuations, the efficient allocation involves the buyer with the highest valuation of each pair obtaining a good. We therefore have $W\left(\mathcal{N}_{2}\right)=2\left(\bar{z}+\mu^{1: 2}(\sigma)\right)-4 c-2 \alpha$. We compare the welfare of industrial structures using the triangle rule that gives the relationship between order statistics from different-sized draws from a given distribution: ${ }^{29}$

$$
\mu^{n: m-1}=\frac{m-n}{m} \mu^{n: m}+\frac{n}{m} \mu^{n+1: m} .
$$

Advantages of networks: capacity sharing and flexibility. Our first result demonstrates that for every $\sigma>0$ there are $\operatorname{costs}(c, \alpha)$ such that a network industrial structure is efficient. For $\sigma>0$, there is dispersion in buyers' valuations, and welfare can be higher when buyers share the capacity of sellers. A vertically integrated buyer that suffers a large negative shock may "regret" having built the productive capacity. In a network, there are fewer units of productive capacity, and buyers suffering the largest negative shocks do not procure inputs. Instead, inputs are allocated flexibly to the buyers with higher valuations.

Proposition 1. In any industry with $\bar{B} \geq 2$ buyers, let $\Theta(\sigma)$ be the set of all cost pairs $(c, \alpha)$ such that a network industrial structure is efficient. For any $\sigma>0$, the set $\Theta(\sigma)$ is nonempty and contains an open set of costs $(c, \alpha)$.

Proof. See the Appendix.

We illustrate this proposition by comparing $W\left(\mathcal{N}_{1}\right)$ with $W(\mathcal{V})$ and $W(X): W\left(\mathcal{N}_{1}\right) \geq W(\mathcal{V})$ when

$$
\left[\mu^{1: 4}(\sigma)+\mu^{2: 4}(\sigma)\right]-6 c \geq 2(\bar{z}-\alpha) .
$$

The left-hand side captures the relative benefits of the network. Because the buyers with two highest valuations obtain goods, there is a gain of $\left[\mu^{1: 4}(\sigma)+\mu^{2: 4}(\sigma)\right]$. However, the multiple links that create the flexibility in the network generate a cost of $6 c$. As for vertical integration, the two additional units of capacity each generate a surplus of $\bar{z}$ but add the investment $\cos t \alpha$, as seen on the right-hand side. Rearranging, we see that for high capacity costs and low link costs, the network dominates vertical integration-W( $\left.\mathcal{N}_{1}\right) \geq W(\mathcal{V})$ when $c$ and $\alpha$ satisfy the following inequality:

$$
\alpha-3 c \geq \bar{z}-\frac{1}{2}\left[\mu^{1: 4}(\sigma)+\mu^{2: 4}(\sigma)\right]
$$

\footnotetext{
${ }^{28} \mathcal{N}_{1}$ is an allocatively complete network (Kranton and Minehart, forthcoming (a)).

${ }^{29}$ See David (1989). We use it to obtain, for example, $W\left(\mathcal{N}_{2}\right)=2 \bar{z}+\mu^{1: 4}+2 / 3 \mu^{2: 4}+1 / 3 \mu^{3: 4}-4 c-2 \alpha$.
} 
Comparing the network to no investment, we have $W\left(\mathcal{N}_{1}\right) \geq W(X)=0$ when $c$ and $\alpha$ satisfy the following inequality:

$$
\alpha+3 c \leq \bar{z}+\frac{1}{2}\left[\mu^{1: 4}(\sigma)+\mu^{2: 4}(\sigma)\right] .
$$

For low capacity costs and low link costs, the network dominates no investment.

Together these two comparisons give us the set of costs $(c, \alpha)$ where $\mathcal{N}_{1}$ yields higher welfare than $\mathcal{V}$ or $X$. Figure 3 shows the values of $c$ and $\alpha$ that satisfy both inequalities, in the region labelled $\mathcal{N}_{1}$. In the region labelled $\mathcal{V}$, vertical integration yields greater welfare, and in the region labelled $X$, no investment should take place. The set $\Theta(\sigma)$, where a network industrial structure is efficient, contains all costs in the region $\mathcal{N}_{1}$. Proposition 1 shows that there is always a network such that a nonempty region exists for any $\bar{B} \geq 2$ and $\sigma>0$.

Proposition 1 and Figure 3 demonstrate the importance of networks as an industrial structure. Without networks, specialized inputs should be produced only when $\alpha \leq \bar{z}$. With networks, we see that specialized inputs should be produced for a larger range of capacity costs. In addition, there is a range where investments that could be made by vertically integrated firms should instead be made in networks - the area where $\alpha \leq \bar{z}$ but $\mathcal{N}_{1}$ yields greater welfare.

Dispersion. Dispersion in buyers' valuations is the source of the economies of sharing in networks. We should therefore expect networks to yield higher welfare as dispersion increases. Our next proposition demonstrates this result. We show, first, that the gains from trade in any network increase as the dispersion of buyers' valuations, $\sigma$, increases. Second, the region of costs where networks are efficient expands.

To show this, we provide a simple characterization of gains from trade in a network. The maximal expected gains from trade in a network can always be written as a constant plus a weighted sum of order statistics. The summation reflects that buyers

\section{FIGURE 3}

INVESTMENT COSTS WHERE NETWORK YIELDS GREATER WELFARE

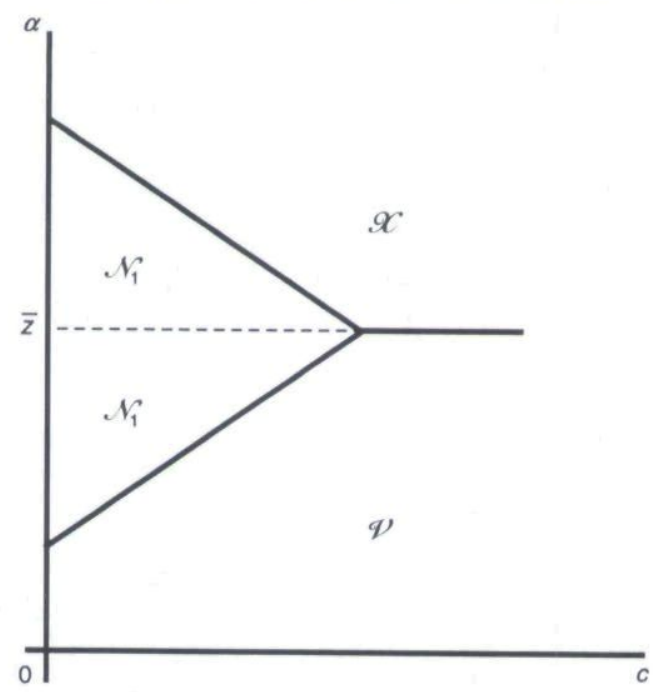


with higher valuations obtain goods whenever possible. We see these sums in the gains from trade of the networks calculated above: For $\mathcal{N}_{1}$ we have $2 \bar{z}+\mu^{1: 4}(\sigma)+\mu^{2: 4}(\sigma)$, and for $\mathcal{N}_{2}$ we have $2 \bar{z}+2 \mu^{1: 2}(\sigma)$ ).

Lemma 1. The maximal expected ex post gains from exchange in a network with $B$ buyers and $S$ sellers can be expressed as $\tilde{S} \bar{z}+\sum_{i=1}^{B} \beta_{i} \mu^{i: B}(\sigma)$, where $\tilde{S} \leq S, \beta_{i} \in \mathbb{R}$, and $\sum_{i=1}^{B} \beta_{i} \mu^{i: B}(\sigma) \geq 0$.

Proof. See the Appendix.

With this result we can readily see that expected gains from trade in a network are always increasing in $\sigma$. Recall that the expectation $\mu^{i: B}(\sigma)$ is homogenous of degree one in $\sigma$. Hence, a sum $\sum_{i=1}^{B} \beta_{i} \mu^{i: B}(\sigma) \geq 0$ is weakly increasing in $\sigma{ }^{30}$

We show that the welfare of an efficient network is strictly increasing in $\sigma$. The welfare of nonnetwork structures is constant in $\sigma$. Therefore, we have the following result:

Proposition 2. (i) In any network, the expected ex post gains from trade are increasing in $\sigma$, the dispersion of buyers' idiosyncratic shocks. (ii) The set of investment costs where a network industrial structure is efficient expands as the dispersion of shocks increases. That is, $\Theta(\sigma) \subset \Theta(\tilde{\sigma})$ for $\sigma<\tilde{\sigma}$.

Proof. See the Appendix.

In our example, it is easy to see that the set of costs where networks are efficient expands. As $\sigma$ increases, the region $\mathcal{N}_{1}$ expands. From the inequalities (1) and (2), we see that the upper (lower) boundary shifts up (down), and the intersection point moves right.

Network form: a tradeoff between link costs and flexibility. The welfare comparison of industrial structures also depends on how much firms in networks are interlinked. Networks with fewer links may yield greater welfare when $c$ is high. There is less flexibility in input allocation, but there is a savings of link costs. Formally, we say a network $\mathcal{N}^{\prime}$ is less connected than a network $\mathcal{N}$ when $\mathcal{N}^{\prime}$ is a subgraph of $\mathcal{N}$ (i.e., removing links from $\mathcal{N}$ yields $\mathcal{N}^{\prime}$ ).

To illustrate, consider $W\left(\mathcal{N}_{2}\right)$ and $W\left(\mathcal{N}_{1}\right) \cdot \mathcal{N}_{2}$ is less connected than $\mathcal{N}_{1}$. In $\mathcal{N}_{2}$ all the buyers are in fact single sourcing. $W\left(\mathcal{N}_{2}\right) \geq W\left(\mathcal{N}_{1}\right)$ when $c$ exceeds $1 / 6\left(\mu^{2: 4}(\sigma)-\mu^{3: 4}(\sigma)\right)$, i.e., when the savings in link cost exceeds the losses from allocating an input to the buyer with the third- rather than second-highest valuation. Here we see concretely how demand uncertainty creates economies of scale. As in the "repairman problem" (Feller, 1950; Rothschild and Werden, 1979), one four-buyer-two-seller network yields greater gains from trade than two two-buyer-one-seller networks. The inputs in the combined network may be more efficiently allocated to the four buyers. ${ }^{31}$ Since $\mu^{2: 4}(\sigma)$ and $\mu^{3: 4}(\sigma)$ are homogeneous of degree one in $\sigma$, as $\sigma$ increases $\left[\mu^{2: 4}(\sigma)-\mu^{3: 4}(\sigma)\right]>0$ increases, and the ability to allocate inputs to the buyer with the second-highest valuation becomes more important..$^{32}$

${ }^{30}$ We could also prove this result using the facts (i) for $\tilde{\sigma}>\sigma$, the distribution $G_{\tilde{\sigma}}(\epsilon)$ is a mean-preserving spread of $G_{\sigma}(\epsilon)$, and (ii) the welfare of any network is a convex function of $\sigma$.

${ }^{31}$ The differences between these networks are also reflected in the comparison between $\mathcal{N}_{2}$ and vertical integration. We see that $W\left(\mathcal{N}_{2}\right) \geq W(\mathcal{V})$ is $\alpha \geq \bar{z}-\left[1 / 2 \mu^{1: 4}+1 / 3 \mu^{2: 4}+1 / 6 \mu^{3: 4}\right]-2 c$. Compare this to the inequality $W\left(\mathcal{N}_{1}\right) \geq W(\mathcal{V})$.

${ }^{32}$ Comparing $W\left(\mathcal{N}_{1}\right)$ and $W\left(\mathcal{N}_{2}\right)$ also shows diminishing returns to adding links. Removing a link from the less connected network, $\mathcal{N}_{2}$, reduces the surplus of exchange by $1 / 2\left(\mu^{1: 4}-\mu^{4: 4}\right)+1 / 6\left(\mu^{2: 4}-\mu^{3: 4}\right)$, whereas removing a link from $\mathcal{N}_{1}$ reduces the surplus of exchange by only $1 / 6\left(\mu^{2: 4}-\mu^{3: 4}\right)$. 
In general, we show that the difference between the welfare of a network and a less connected network where the same number of sellers sell goods is increasing in the dispersion of buyers' idiosyncratic shocks. The result implies that networks should be more connected when firm-specific shocks in an industry are high.

Proposition 3. The difference between the welfare of a network and any less connected network, where the same number of sellers sell goods, is increasing in the dispersion of buyers' idiosyncratic shocks.

\section{Proof. See the Appendix.}

Propositions 1, 2, and 3 together describe a strong connection between idiosyncratic demand shocks and the efficiency of networks. The example illustrates this connection, and Figure 4 summarizes the welfare comparison of the four industrial structures as a function of the cost of productive assets, $\alpha$, and the cost of links, $c$, for a given dispersion $\sigma$ of buyers' valuations. ${ }^{33}$

In the regions marked $\mathcal{V}$, each buyer should build its own unit of productive capacity. In the regions marked $\mathcal{N}_{1}$ and $\mathcal{N}_{2}$, the buyers should form a network. In the region marked $X$, investment costs are so high that it is not optimal to produce specialized inputs. Figure 4 shows how more connected networks become more important as buyers' valuations become more dispersed. As $\sigma$ increases, the combined area $\mathcal{N}_{1}+\mathcal{N}_{2}$ expands. The area $\mathcal{N}_{1}$ expands at the expense of area $\mathcal{N}_{2}$, as well as areas $X$ and $\mathcal{V}$. With greater dispersion of buyers' valuations, more connected networks are the socially preferred industrial structure.

In the Appendix (Figures A1 and A2), we expand our example to consider all possible industrial structures for four buyers, allowing for $S=\{1,2,3\}$ sellers. We find that a network industrial structure involving both a network and a vertically integrated firm is efficient near the boundaries in Figure 4 between $\mathcal{V}$ and $\mathcal{N}_{1}+\mathcal{N}_{2}$. Near the boundaries of $x$ and $\mathcal{N}_{1}+\mathcal{N}_{2}$, there is an efficient industrial structure where some buyers are in a network and one buyer does not invest. Overall, compared to Figure 4, the area in which network industrial structures is efficient is larger (because more structures are considered), and the area is more finely subdivided into structures with networks of more or fewer sellers.

\section{Strategic firms and industrial structure}

- In this section we consider whether strategic firms, acting in their own self-interest, will form efficient industrial structures. We analyze a two-stage noncooperative game. In the first stage, firms invest in productive capacity and links. In the second stage, production and exchange takes place. This stage represents the possibly many period returns to first-stage investments.

This formulation implicitly assumes that firms cannot use long-term contingent contracts to assign investments, future prices, or allocations of goods. It thus embodies the now standard Grossman and Hart (1986) and Hart and Moore (1990) incompletecontracts framework: agents must make investments before uncertainty is resolved and contingent contracts are not possible. Rather, a firm makes first-stage investments considering how its actions affect future ability to obtain inputs and its competitive or bargaining position. Case studies of networks show that firms do not use long-term contracts to set prices and investment level. Payments are often determined or adjusted ex post through informal negotiations (Uzzi, 1996; Nishiguchi, 1994).

${ }^{33}$ The equations for all boundaries of the regions are provided in the Appendix. 


\section{FIGURE 4}

\section{INVESTMENT COSTS WHERE MORE OR LESS CONNECTED YIELD GREATER WELFARE}

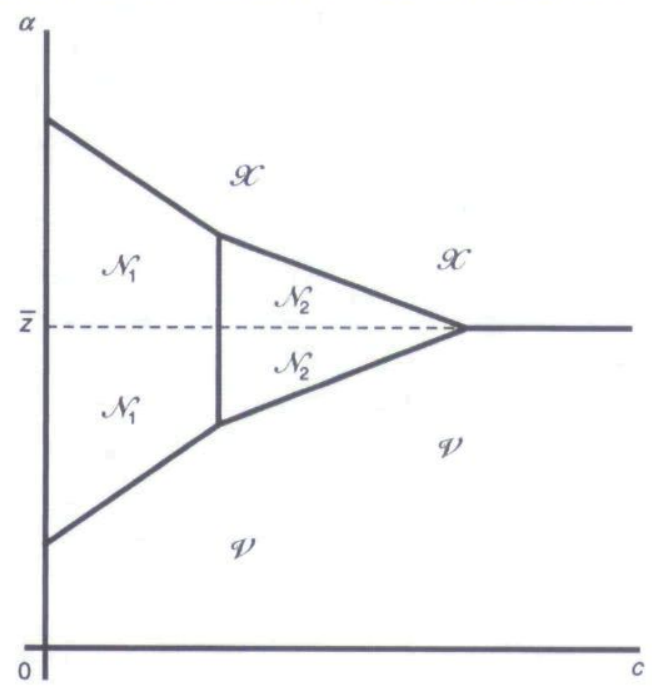

In the absence of long-term contracts, individual investment incentives are not necessarily aligned with economic welfare. Vertically integrated buyers, of course, need not worry about bargaining and holdup. But in networks, the nature of the secondstage competition for inputs and the division of surplus will influence firms' investment decisions. A buyer's investment in a link to a seller is a specific investment, and the buyer must concern itself with the possibility of holdup. A seller's investment in a productive asset is quasi-specific, and it must also be concerned with obtaining a sufficient return.

We consider two ways surplus can be divided among firms in a network. First we consider firms' Shapley values. The Shapley value captures the notion of equal bargaining power; a buyer and seller gain equally from their relationship. It is a weighted average of a firm's contribution to all possible groups (coalitions) of firms and is a standard way to represent bargaining power. ${ }^{34}$

Second, we consider a representation of competition for inputs. This formulation of revenues emphasizes the interaction of supply and demand in a network. As in assignment games (Shapley and Shubik, 1972; Roth and Sotomayor, 1990), we consider revenues that are pairwise stable: ex post no linked buyer and seller can strike a deal that would make both better off. ${ }^{35}$ We consider, in particular, the stable payoffs that give buyers the highest possible level of surplus. These revenues are equivalent to those that arise in an ascending-bid auction model of competition (Demange, Gale, and Sotomayor, 1986; Kranton and Minehart, forthcoming (a) and (b)). As in a competitive market with a "Walrasian auctioneer," at the equilibrium prices, supply equals demand given the pattern of links.

${ }^{34}$ For the Shapley value in graphs, see Aumann and Myerson (1988), Myerson (1977), and Jackson and Wolinsky (1996). Hart and Moore (1990) use the Shapley value to study how ownership structures affect agents' investment incentives. We discuss their results below. Recent work on specific investments that employ the Shapley value includes Rajan and Zingales (1998) and Segal and Whinston (1998).

${ }^{35}$ Kranton and Minehart (forthcoming (b)) consider general properties of pairwise stable payoffs in networks. 
These two revenue rules provide theoretical benchmarks of how competition for inputs and bargaining can affect firms' investment decisions. In the competitive framework, with its emphasis on supply and demand, a buyer earns the marginal value of its participation in a network. The Shapley value, in contrast, gives each firm a share of the inframarginal gains from trade. We will see that these different divisions of surplus lead to different predictions as to whether an efficient industrial structure will emerge.

$\square \quad$ The game. There are $\bar{B}$ buyers and $\bar{S}$ specialized sellers.

Stage 1. Buyers simultaneously choose to invest in a dedicated asset, to form links with specialized sellers, or not to invest. A buyer incurs a cost $\alpha$ if it vertically integrates, and incurs a cost $c$ for each link to a specialized seller. At the same time, each of the $\bar{S}$ sellers chooses whether or not to invest in a flexible asset, incurring a cost $\alpha$ if it does. These actions yield an industrial structure $\mathcal{G}$ that is observable to all players. ${ }^{36}$

Stage 2. Buyers' valuations of goods are realized and, in the simplest case, observed by all players. ${ }^{37}$ Production and exchange takes place. Firms earn revenues that we express by a reduced-form revenue rule. For a given realization of buyers' valuations, let $r_{i}^{b}(\mathbf{v}, \mathcal{G})$ be buyer $i$ 's revenues in industrial structure $\mathcal{G}$, and let $r_{j}^{s}(\mathbf{v}, \mathcal{G})$ be the revenues of seller $j$. We make several assumptions about the revenue rule. A vertically integrated buyer earns $r_{i}^{b}(\mathbf{v}, \mathcal{G})=v_{i}$. A buyer or seller that does not invest earns $r_{i}^{b}(\mathbf{v}, \mathcal{G})=0$ or $r_{j}^{s}(\mathbf{v}, \mathcal{G})=0$, respectively. The rest of the firms are in networks, and we assume that the surplus a network generates is fully distributed to its constituent firms. ${ }^{38}$ Both revenue rules we consider for networks satisfy this property.

A firm's expected profits in the game are its second-stage expected revenues minus its first-stage investment costs. Let $\prod_{i}^{b}(\mathcal{G}) \equiv E_{\mathbf{v}}\left[r_{i}^{b}(\mathbf{v}, \mathcal{G})\right]-\alpha \cdot \delta_{i}(\mathcal{G})-c \cdot \ell_{i}(\mathcal{G})$ be the expected profits of buyer $i$, and let $\Pi_{j}^{s}(\mathcal{G}) \equiv E_{\mathbf{v}}\left[r_{j}^{s}(\mathbf{v}, \mathcal{G})\right]-\alpha \cdot \kappa_{j}(\mathcal{G})$ be seller $j$ 's profits.

This game is effectively a (one-stage) simultaneous-move game. The graph $\mathcal{G}$ summarizes the firms' strategies, and the profits $\Pi_{i}^{b}(G)$ and $\Pi_{j}^{s}(G)$ give firms' payoffs for each strategy profile. We solve for pure-strategy Nash equilibria. In equilibrium, each firm's investments maximize its profits, given the investments of other firms.

In particular, given other firms' investments, a network industrial structure is an equilibrium outcome if and only if (1) no seller that invests in a flexible asset can earn greater profits by not investing, and vice versa for a seller that does not invest, and (2) no buyer has an incentive to change its investments in links or dedicated assets. For a network industrial structure $\mathcal{G}$, these conditions are, in turn,

$$
\Pi_{j}^{s}(\mathcal{G}) \geq \Pi_{j}^{s}\left(\mathcal{G}_{j}^{\prime}\right)
$$

for each seller $j$ where $\mathcal{G}_{j}^{\prime}$ differs from $\mathcal{G}$ only in the investment of seller $j$, and

$$
\Pi_{i}^{b}(\mathcal{G}) \geq \Pi_{i}^{b}\left(\mathcal{G}_{i}^{\prime}\right)
$$

${ }^{36}$ We discuss below alternative specifications of this investment stage, including sequential moves and seller investment in links.

${ }^{37}$ In the analysis below, we note where the results extend to the case that buyers' valuations are private information.

${ }^{38}$ Formally, we require that the revenue rule be component balanced (Jackson and Wolinsky, 1996). That is, the revenue rule distributes all the surplus from each maximally connected subgraph to nodes in that subgraph. 
for each buyer $i$ and all graphs $\mathcal{G}_{i}^{\prime}$ where $\mathcal{G}_{i}^{\prime}$ differs from $\mathcal{G}$ only in the links or dedicated asset of buyer $i$.

Equilibrium industrial structures. It is easy to support equilibria in which either all buyers are vertically integrated $(\mathcal{V})$ or no firms make any investment $(X)$. A firm's payoff from either is independent of the actions of other firms; no coordination is required. One of these two structures, therefore, is always an equilibrium.

Proposition 4. When $\bar{z} \geq \alpha$, the vertically integrated structure $(\mathcal{V})$ is an equilibrium outcome, and when $\bar{z} \leq \alpha$, the no-investment structure $(X)$ is an equilibrium outcome.

Proof. Given that all buyers are vertically integrated and no seller has invested in a flexible asset, (i) no buyer can earn greater profits by not investing if and only if $\bar{z} \geq \alpha$, and (ii) no buyer has an incentive to deviate and establish a link to a seller. The same argument holds for no-investment for $\alpha \leq \bar{z}$. Q.E.D.

For vertical integration, a buyer's expected profits are also exactly its contribution to economic welfare $(\bar{z}-\alpha)$. Therefore, vertical integration is the unique equilibrium outcome when it is efficient. The same is true when no investment is efficient. ${ }^{39}$

Proposition 5. When the industrial structure $\mathcal{V}$ or $X$ is efficient, it is the unique equilibrium outcome (up to welfare equivalence).

Proof. In the industrial structure $\mathcal{V}$, each buyer earns $\bar{z}-\alpha$ and welfare is $\bar{B} \cdot(\bar{z}-\alpha)$. When $\mathcal{V}$ is efficient, any nonwelfare equivalent industrial structure $I$ generates a strictly smaller welfare. It follows that in $I$ at least one nonintegrated buyer earns profits that are strictly less than $\bar{z}-\alpha$. This buyer could earn $\bar{z}-\alpha$ by vertically integrating. Therefore $I$ is not an equilibrium. A similar argument holds for no investment. Q.E.D.

Firms may not form efficient network industrial structures for exactly the opposite reasons. First, in networks firms' payoffs depend on the investments of the other firms, so coordination failure is possible. If too few buyers, for example, invest in links to sellers, then a particular network will not arise in equilibrium even when it is part of the efficient structure. Second, a buyer's or seller's individual payoffs may not match its contribution to economic welfare. We examine these possibilities using (i) the Shapley value and (ii) a competitive revenue rule.

Shapley value revenue rule. In our first revenue rule, firms earn their Shapley values. The Shapley value defines an agent's bargaining power using a weighted average of the agent's marginal contribution to all possible coalitions of firms. It is a standard way to define bargaining power in groups of agents and appears in other research on supply structures (e.g., Hart and Moore, 1990). For buyer $i$ we have

$$
r_{i}^{b}(\mathbf{v}, \mathcal{G})=\sum_{C}\left[w\left(A^{*}\left(\left.\mathbf{v}\right|_{C+b_{i}},\left.\mathcal{G}\right|_{C+b_{i}}\right)\right)-w\left(A^{*}\left(\left.\mathbf{v}\right|_{C},\left.\mathcal{G}\right|_{C}\right)\right)\right] \frac{|C| !((S+B)-|C|-1) !}{(S+B) !},
$$

where $B(S)$ is the number of buyers (sellers) in the network, $C$ is a set of firms, $\left.\mathbf{v}\right|_{C}$ are the valuations of the buyers restricted to $C$, and $\left.G\right|_{C}$ is the industrial structure restricted to investments of the firms in $C$. We have a similar formula for a seller $j$. As

${ }^{39}$ The equilibria are unique up to welfare equivalence. Two industrial structures are welfare equivalent if they generate the same economic welfare. For instance, in the degenerate case that $\bar{z}=\alpha, \mathcal{V}$ and $X$ are welfare equivalent because both yield zero economic welfare. If, in addition, prohibitively expensive links rule out a network alternative, then $\mathcal{V}$ and $X$ are both equilibrium outcomes. 
mentioned above, this revenue rule gives equal bargaining power to linked buyers and sellers; removing a link between a buyer $i$ and seller $j$ reduces their respective revenues by the same amount. The Shapley value is the only revenue rule satisfying this property. ${ }^{40}$

While the equal bargaining power property may seem natural, Shapley values distort firms' investment incentives. Intuitively, a firm's Shapley value is based on both its inframarginal and marginal contributions to network welfare. Because of the role of inframarginal contributions, equilibrium conditions for both buyers and sellers diverge from efficiency criteria.

We illustrate with network industrial structure $\mathcal{N}_{1}$ from Figure 2 . In vertical integration, a buyer earns exactly its marginal contribution to economic welfare. If all agents' network revenues were equivalent to their marginal contributions to network welfare, efficient industrial structures would always be equilibrium outcomes. When the revenue rule is given by the Shapley value, however, this is not the case. In $\mathcal{N}_{1}$, the marginal contribution of buyer 1 to expected surplus from exchange is $1 / 2\left[\mu^{1: 4}-\mu^{3: 4}\right] .^{41}$ In contrast, the Shapley value for buyer 1 yields the following expected revenues:

$$
E_{\mathbf{v}}\left[r_{1}^{b}\left(\mathbf{v}, \mathcal{N}_{1}\right)\right]=\frac{7}{60} \bar{z}+\frac{1}{6} \mu^{1: 4}+\frac{47}{360} \mu^{2: 4}-\frac{11}{360} \mu^{3: 4}
$$

This value is a weighted sum of buyer 1's marginal contribution to all possible coalitions of agents. It bears no simple relationship to buyer 1's contribution to the grand coalition, that is, the network as a whole.

In general, we find that the Shapley value may be greater or less than an agent's marginal contribution to a network. This ambiguity arises because the relationship between an agent's marginal contribution to a coalition and the size of the coalition is nonmonotonic. On the one hand, an agent's marginal contribution to smaller coalitions could be larger than its contribution to the grand coalition. In $\mathcal{N}_{1}$, buyer 1 contributes $\bar{z}$ to the coalition of buyer 1 and seller 1 . When $\bar{z}$ exceeds $1 / 2\left[\mu^{1: 4}-\mu^{3: 4}\right]$, buyer 1 's contribution to this small coalition exceeds its marginal contribution to the whole network. On the other hand, an agent's contribution to smaller coalitions could be smaller than its marginal contribution to the grand coalition. In $\mathcal{N}_{1}$, buyer 1 contributes nothing to the coalition of buyer 1 and seller 2 . For buyer 1 in $\mathcal{N}_{1}$, the second possibility dominates under mild assumptions on the distribution of shocks, i.e., the distribution of $\epsilon_{i}$ is symmetric around zero, and $\mu^{1: 4}>1 / 2 \bar{z}$.

Because the Shapley value does not give a buyer the marginal social value of its network links, buyers may have the incentive to add inefficient links or cut efficient links. Adding a link can increase the contribution the buyer makes to small coalitions, even if the link does not increase total welfare. On the other hand, a buyer must share the value of a link with the seller (equal bargaining power property). Therefore, sometimes a buyer would not have an incentive to invest in a link, even if it is efficient.

A similar analysis applies to sellers' equilibrium conditions. For sellers in the example, calculations show that when the distribution of $\epsilon_{i}$ is symmetric around zero,

${ }^{40}$ Let $\mathcal{G}-i j$ denote the graph $\mathcal{G}$ except for any link between buyer $i$ and seller $j$. The equal bargaining power property holds if and only if $r_{i}^{b}(\mathbf{v}, \mathcal{G})-r_{i}^{b}(\mathbf{v}, \mathcal{G}-i j)=r_{j}^{s}(\mathbf{v}, \mathcal{G})-r_{j}^{s}(\mathbf{v}, \mathcal{G}-i j)$ for all $\mathcal{G}$, buyers $i$, sellers $j$, and realizations of $\mathbf{v}$. Jackson and Wolinsky (1996) extend a Myerson (1977) result to show that the Shapley value is the only component balanced revenue rule with this property.

${ }^{41}$ The difference in surplus from exchange when buyer 1 is in the network and when buyer 1 is not is $\mu^{1: 4}+\mu^{2: 4}-\left[\mu^{1: 3}+\mu^{2: 3}\right]$. Using the triangle rule, this simplifies to $1 / 2\left[\mu^{1: 4}-\mu^{3: 4}\right]$. 
the Shapley value is less than a seller's marginal contribution to total welfare. Therefore, in this case, each seller has insufficient incentive to invest in the productive asset.

The ambiguity of agents' investment incentives contrasts with the Shapley value results of Hart and Moore (1990). In their model, agents also make investments in advance of production. They find that the Shapley value gives all agents insufficient investment incentives. As they discuss, this result follows from their assumption that an agent's marginal contribution to a coalition always increases with coalition size. That is, they assume a form of complementarity. ${ }^{42}$ This assumption contrasts with the nonmonotonic relationship between marginal contribution and coalition size that arises in our model. Rajan and Zingales (1998) and Segal and Whinston (1998) also find that investment incentives under the Shapley value may be either inefficiently high or inefficiently low. These models study settings different from ours, but the ambiguity of investment incentives similarly derives from nonmonotonic relationships between marginal contributions and coalition size..$^{43}$

Competitive revenue rule. We now turn to our second revenue rule, which we call the competitive revenue rule. These revenues are pairwise stable: ex post no linked buyer and seller can strike a deal that would make both better off. ${ }^{44}$ For every graph and every realization of buyers' valuations, there is an efficient allocation of goods, and there is a price vector that determines the split of surplus between buyers and sellers. We use the price vector that is best for buyers. These prices can also be represented as the outcome of an ascending-bid auction. Ascending-bid auctions are known to have many efficiency properties, particularly when buyers' valuations are private information. Both the auction and pairwise stability capture a competitive environment where the interaction between supply and demand determines final revenues. ${ }^{45}$

The supply and demand character of these revenues can be seen easily in the auction formulation. In a network, suppose sellers simultaneously hold ascending-bid auctions; that is, the price rises from zero at the same time in each auction. Buyers can bid only in the auctions of their linked sellers. The price rises from zero until demand no longer exceeds supply for some subset of sellers. These sellers then sell their goods at that price, and the price continues to rise until all sellers have sold their output. In this auction it is an equilibrium following elimination of weakly dominated strategies for each buyer to remain in the bidding of its linked sellers' auctions until the price reaches its valuation of an input (Kranton and Minehart, forthcoming (a)).

To see this outcome, consider the network $\mathcal{N}_{1}$ and suppose buyers' idiosyncratic shocks are realized in the following order: $\epsilon_{1}>\epsilon_{2}>\epsilon_{3}>\epsilon_{4}$. The price rises until $p=z+\epsilon_{4}$, when buyer 4 drops out of the bidding. Buyers 1,2 , and 3 remain in the bidding for the two sellers' goods and so demand for these goods exceeds their supply. At $p=z+\epsilon_{3}$, buyer 3 drops out of the bidding. The two sellers are now collectively

${ }^{42}$ Hart and Moore (1990) assume assets are general; an agent's investment increases the value of any coalition of which the agent is a part. It is further assumed that "the marginal return on investment increases with the number of other agents and assets in the coalition" (p. 1127). In contrast, assets in our model are specific. An investment may have no impact on the value of some coalitions.

${ }^{43}$ In Rajan and Zingales (1998), managers make investments that are specific to a common entrepeneur. Only coalitions that contain the entrepeneur ever have positive value. Segal and Whinston (1998) consider investments by a buyer and two sellers when one of the sellers may have an exclusive contract. Only coalitions that contain the buyer ever have positive value. Welfare depends on whether the investments are substitutes or complements.

${ }^{44}$ Since only buyer-seller pairs generate surplus, pairwise stable payoffs are equivalent to core payoffs (Shapley and Shubik, 1972).

${ }^{45}$ See Kranton and Minehart (forthcoming (b)) for an analysis of pairwise stable payoffs in networks and Kranton and Minehart (forthcoming (a)) for auction details and proofs. 
linked to only two buyers, and there is an allocation in which each buyer procures a good. So both auctions clear at the common price $p=z+\epsilon_{3}$. The price $p$ is the lowest price such that supply for a subset of sellers' goods equals the demand.

With these competitive revenues, a buyer's expected payoff exactly equals its marginal contribution to the network (Kranton and Minehart, forthcoming (a)). Buyers do not earn any inframarginal surplus. Rather, a buyer who obtains an input earns the difference between its valuation and the valuation of the "next-best" buyer. The price a buyer pays is equal to the social opportunity cost of obtaining the good. In the example above, buyer 1 paid a price $z+\epsilon_{3}$, which is the surplus that would have accrued had buyer 3 purchased an input instead of buyer 1 . The revenue rule in the example is ${ }^{46}$

$$
\begin{array}{llll}
r_{1}^{b}\left(\mathbf{v}, N_{1}\right)=\epsilon_{1}-\epsilon_{3} & r_{2}^{b}\left(\mathbf{v}, N_{1}\right)=\epsilon_{2}-\epsilon_{3} & r_{3}^{b}\left(\mathbf{v}, N_{1}\right)=0 & r_{4}^{b}\left(\mathbf{v}, N_{1}\right)=0 \\
r_{1}^{s}\left(\mathbf{v}, \mathcal{N}_{1}\right)=z+\epsilon_{3} & r_{2}^{s}\left(\mathbf{v}, \mathcal{N}_{1}\right)=z+\epsilon_{3} . &
\end{array}
$$

An immediate implication is that network equilibrium conditions for buyers are aligned with economic welfare. Buyers' incentives are also aligned with economic welfare under vertical integration and not investing (Proposition 5). Therefore, buyers will make the efficient choice between vertical integration, networks, and not investing, and if a buyer participates in a network, it chooses its links efficiently given the investments of the other firms. We have

Proposition 6. When firms' revenues are given by the competitive revenue rule, buyers make investments if and only if the investments increase social welfare, given the choices of the other firms.

Unfortunately, sellers' investment incentives are not aligned with economic welfare. They earn less than their marginal contributions to a network. A seller's marginal contribution equals the valuation of the buyer that obtains its good. A seller's revenues, however, are the valuation of the "next-best" buyer of the good. For example, in network $\mathcal{N}_{1}$ each seller earns expected revenues of $\bar{z}+\mu^{3: 4}$. This is less than the seller's expected marginal contribution, which is $\bar{z}+1 / 4 \mu^{1: 4}+3 / 4 \mu^{2: 4}$. Under the competitive revenue rule, the region where a network is both an equilibrium and efficient is, therefore, restricted only by sellers' equilibrium conditions.

The notion that competition can lead to efficient investment appears elsewhere in the literature. For example, Acemoglu (1996) obtains this result for the Walrasian equilibrium in a model with a continuum of agents. With small numbers of agents, it is more difficult to achieve efficient investment incentives. Mechanisms that give each agent its marginal contribution to total welfare are, in general, only implementable if at least one agent has no incentive problem and can be made a residual claimant. In our competitive revenue rule, one type of agent (the buyer) always receives its marginal contribution. ${ }^{47}$ The sellers act as residual claimants and their investment incentives are compromised..$^{48}$

${ }^{46}$ These revenues apply to any $\mathbf{v}$ with the same ordering. Expected revenues (taken over all $\mathbf{v}$ ) are $E_{\mathbf{v}}\left[r_{i}^{b}\left(\mathbf{v}, \mathcal{N}_{1}\right)\right]=1 / 4\left(\mu^{1: 4}-\mu^{3: 4}\right)+1 / 4\left(\mu^{2: 4}-\mu^{3: 4}\right)$ and $E_{\mathbf{v}}\left[r_{j}^{s}\left(\mathbf{v}, \mathcal{N}_{1}\right)\right]=\bar{z}+\mu^{3: 4}$.

${ }^{47}$ These are the only payoffs (up to a constant) for buyers that would achieve an efficient allocation when valuations are private information. This result follows from Myerson's (1981) payoff equivalence theorem.

${ }^{48}$ Our inefficiency result for sellers' investments may be viewed as a consequence of incomplete contracting. A long-term contract could establish the efficient industrial structure, even if investments are not contractible (Rogerson, 1992). For an overview of the literature on incomplete contracting, see Tirole (1999). 
$\square$ Second-best equilibrium networks. This section shows that despite the problems in achieving an efficient network structure, equilibrium network structures do exist. These network equilibria always yield greater welfare than vertical integration and noinvestment. Hence, in equilibrium, network industrial structures, while not first best, are second best.

The next proposition shows that with competitive revenues, there always exist network equilibria if there is any dispersion in the idiosyncratic shocks $(\sigma>0)$, and if there are at least three buyers in the industry. We have

Proposition 7. With the competitive revenue rule and for $\bar{B} \geq 3$, for any $\sigma>0$ there is a nonempty set of $(c, \alpha)$ pairs of investment costs $\Omega(\sigma)$ such that if $(c, \alpha) \in \Omega(\sigma)$, a network industrial structure is an equilibrium.

\section{Proof. See the Appendix.}

Similar to Proposition 1 (illustrated in Figure 3), there is a region of investment costs where a network industrial structure is an equilibrium outcome. Intuitively, a network industrial structure is an equilibrium when link costs, $c$, are sufficiently small and capacity costs, $\alpha$, sufficiently large so that buyers are willing to invest in networks rather than build their own supply facility. Capacity costs cannot be too large, however, to ensure that sellers have the incentive to invest.

With the Shapley revenue rule, network equilibria can exist when there is sufficient dispersion of buyers' idiosyncratic shocks. Although the investment incentives of both buyers and sellers are distorted, a sufficiently high value of the dispersion $\sigma$ ensures that a network generates enough surplus so that all equilibrium conditions are satisfied. ${ }^{49}$

Not only do network equilibria exist, but these equilibrium structures always yield greater welfare than vertical integration or no-investment. The proof of Proposition 5 tells us that when either vertical integration or no-investment is the efficient industrial structure, it is the unique equilibrium outcome. The same argument yields the result that when an industrial structure containing a network is an equilibrium outcome, it must yield higher welfare than either of these alternatives. That is, despite the inefficiencies that arise from incomplete contracting, firms may form welfare-enhancing, disintegrated industrial structures.

$\square \quad$ Alternative specifications of the investment game. In this section we briefly discuss alternative specifications of the investment game.

In our analysis we have assumed that buyers unilaterally build links to sellers and bear the full cost of these links. Sellers, of course, might also select links and bear part of the link cost. To accommodate this possibility, suppose that in the first stage of the game, buyers and sellers simultaneously invest in their shares of links. This specification will affect both of the problems discussed above in establishing efficient networks: (i) coordination and (ii) payoffs that do not match the marginal contribution to economic surplus.

First, when sellers must also invest in links, greater coordination will be necessary to establish networks in equilibrium. Buyers and sellers must coordinate on the same

${ }^{49}$ In the Appendix, we prove that a network equilibrium exists for sufficiently high values of the dispersion parameter $\sigma$. The result is restricted to values of $\sigma$ for which all realizations of buyers' valuations are positive. We provide an example for uniformly distributed idiosyncratic shocks. 
links. This problem could be solved by a sequential-move link formation game, but such games may involve more subtle coordination problems. ${ }^{50}$

Second, revenue rules, even competitive rules, may not align the investment incentives of all agents simultaneously. Under both revenue rules, sellers do not have sufficient incentive to invest in productive assets. This problem could be exacerbated when sellers also invest in links. The logic of the second-best results, however, would still apply. Despite underinvestment in links, network equilibria would exist and yield greater welfare than vertical integration.

Another interesting specification is multiple unit demand and supply. In this case, a vertically integrated buyer could smooth of some of its demand uncertainty internally. Like a network, the firm would have fewer units of dedicated capacity than the number of units demanded. This possibility would reduce, but not eliminate, the welfare advantage of external supply networks. ${ }^{51}$ In a model of strategic network formation, the Shapley value revenue rule could easily be extended to this case. The investment results would be similar. As for competitive payoffs, Gul and Stacchetti (forthcoming) provide an ascending-bid auction for a setting with multiple buyers that have multiple unit demand and multiple suppliers with multiple supply. The prices that arise, however, do not always correspond to the Vickrey prices, i.e., prices such that buyers pay the social opportunity cost of obtaining a good, as in the present article. Developing an auction that achieves Vickrey prices, or understanding why such an auction is not possible, could shed light both on auction theory and investment incentives in networks. ${ }^{52}$

\section{Ownership and vertical merger}

- Because network equilibria are second best, the question arises of whether alternative ownership structures might improve on network welfare. In this section we consider an example of an ownership structure where a buyer owns a flexible asset. We ask whether such an ownership structure improves on investment incentives. ${ }^{53}$

We build on our basic model as follows. In addition to buyers and sellers, there can be upstream units and downstream units of a single firm. In the first stage of the game, owners of the units decide whether or not to invest in links and/or flexible productive capacity. In the second stage, valuations are realized and production and exchange take place. We assume that second-stage revenues accrue to each unit's owner according to the competitive revenue rule. With this rule, asset use is efficient. ${ }^{54} \mathrm{By}$

${ }^{50}$ When buyers build links before sellers, the subsequent actions of sellers could potentially depend on extraneous links that carry no productive value (e.g., links to noninvesting sellers). See Jackson and Wolinsky (1996) for a different approach to these coordination issues. They examine networks that satisfy a pairwise stability condition with respect to investments.

${ }^{51}$ When a group of buyers share sellers, gains from trade would be higher, since in expectation the top valuations of $N \geq 2$ buyers is higher than those of a single buyer.

${ }_{52}$ To the best of our knowledge, such an auction has not yet been developed nor ruled out. Ausubel (1997) considers multiple buyers each with multiple unit demand and a single seller that can sell multiple units. He develops an ascending-bid auction where, in an equilibrium, buyers pay Vickrey prices.

${ }^{53}$ One possibility is for all the units to be under common ownership. Indeed, complete merger would lead to efficient investments. However, this outcome seems unlikely in many economic settings because complete merger would be either illegal because of antitrust considerations or suboptimal for unmodelled reasons such as diminishing returns to managerial effort.

${ }^{54}$ Regardless of the ownership structure, asset use will be efficient if the owner of an upstream asset produces an input for a linked downstream asset whenever it is efficient to do so. We can see this easily in the auction formulation of the competitive revenue rule. The owner of downstream unit $i$ with a link to its own upstream asset will produce an input for a linked downstream asset $j$ when $j$ is willing to pay a price higher than $v_{i}$. 
fixing the revenue rule, we are able to identify the changes in investment incentives that come from a change in ownership structure.

Consider network $\mathcal{N}_{1}$ in Figure 2. We compare the equilibrium conditions for investment to the efficiency conditions for this industrial structure under two ownership structures. The first is the ownership structure previously analyzed. The second is the same, except buyer 2 and seller 1 are merged.

First, consider the original structure. By Proposition 6, the buyers make link investments optimally given the choices of other firms. However, sellers earn expected revenues that are less than the seller's marginal contribution. ${ }^{55}$ Because of this shortfall, network $\mathcal{N}_{1}$ may fail to be an equilibrium when it is efficient.

Consider next the ownership structure in which there is a single firm encompassing the upstream unit of seller 1 and the downstream unit of buyer 2 . We will refer to this merged entity as $M$. We ask whether $M$ has a greater incentive than andependent seller 1 to invest in the flexible asset, taking the other investments as given. ${ }^{56}$ We find that $M$ 's incentive to invest in $\alpha$ is indeed higher, because both the upstream and downstream unit earns returns from use of the productive capacity. ${ }^{57}$ Thus, merger mitigates the seller's underinvestment problem. We next consider $M$ 's incentive to invest in the internal link between buyer 2 and seller 1. As in Bolton and Whinston (1993), the incentive to invest in this link is inefficiently strong. ${ }^{58}$ In events where $M$ sells the input of seller 1 to buyer $3, M$ receives a higher price when it has the link than when it does not. This strategic effect raises the value of the link to $M$ above its productive value. Finally, we consider $M$ 's incentive to invest in an external link to seller 2 . This link increases the payoff of buyer 2 but decreases the payoff of seller 1 , which now sometimes loses buyer 2's business to seller 2. We find that this gain and loss exactly cancel: $M$ has no incentive to build the link even though the link is welfare enhancing. ${ }^{59}$

This example reveals a new consequence of vertical merger in a multilateral setting. Buyers that own a network productive facility might not invest in relationships with other sellers, even when such links would be efficient. This result has no analogy in Bolton and Whinston's (1993) setting, because they do not consider the possibility of multiple investments by upstream firms. It also has no analogy in the related literature by Grossman and Hart (1986), Hart and Moore (1990), and others, because investments are usually modelled as a one-dimensional parameter that cannot be targeted at a specific trading partner. ${ }^{60}$ The example demonstrates a general point that in a multilateral environment, partial merger need not unambiguously improve investment incentives even for the merged firms.

${ }^{55}$ See the discussion following Proposition 6.

${ }^{56}$ We take all of buyer 2's link investments as given, including the link to seller 1 . This is because we want to change one investment at a time. Even if we assume that the owner does not build a link to a noninvesting seller, we still find that the incentive to invest in $\alpha$ is stronger under joint ownership.

57 These calculations are available from the authors on request. They are not difficult.

${ }^{58}$ In Bolton and Whinston (1993) there are two downstream firms and one upstream firm. The downstream firms make welfare-enhancing investments in the upstream firm that are somewhat analogous to our link investments. The upstream firm has a random capacity to produce one or two units. When the upstream firm can produce only one unit of input, their bargaining process gives the same division of payoffs as our competitive revenue rule.

59 The surplus added by the link is earned by other agents.

${ }^{60}$ Segal and Whinston (1998) examine multilateral investment incentives in a model with a single buyer and two sellers. Their results cannot be directly compared to ours because they consider exclusive contracting rather than vertical merger and because the relationship between investments and efficiency is different than the one here. They do, however, distinguish between internal and external investments in a related way. 


\section{Conclusion}

This article develops a theory of alternative industrial structures for specialized input production. We contrast vertical integration and networks. Vertically integrated firms invest in their own, dedicated supply facilities. In networks, buyers make specific investments in external suppliers, which in turn invest in quasi-buyer-specific assets. These investments make sellers "flexible specialists" that can produce specialized inputs to linked buyers' specifications.

We examine the social costs and benefits of different industrial structures as well as individual firms' strategic investment incentives. We find that when buyers face large idiosyncratic shocks and productive capacity is costly, more connected networks are the efficient industrial structure. Buyers should have links to multiple sellers and share their capacity. The links allow inputs to be allocated to the buyers with the highest valuations. When contracts are incomplete, however, strategic firms may not have the incentive to form the efficient industrial structure. A firm that builds its own plant always receives the full return to its investments. But in a network, returns to investments depend on the entire pattern of links and the ex post division of surplus. Despite distorted investment incentives, we find that network equilibria exist and are always second-best industrial structures.

Our analysis of strategic firms falls into the general area of incomplete contracting, or holdup, models. The key question in this literature is the extent to which private investment diverges from socially optimal investment when some forms of contracting are not possible. The answer depends on how ex post surplus is allocated among the players. Authors have modelled the ex post division of surplus in many ways, including reduced-form bargaining solutions such as Nash bargaining (e.g., Grossman and Hart, 1986), cooperative solutions such as the Shapley value (e.g., Hart and Moore, 1990; Segal and Whinston, 1998; Rajan and Zingales, 1998), and competition among agents (e.g., Acemoglu, 1996). Our results agree with much of this research. We find that the Shapley value significantly distorts investment incentives. In contrast, the competitive revenue rule fully aligns the incentives of buyers: they make correct investments in networks, and they choose correctly between alternative supply structures.

The network equilibria in this article might resolve part of the puzzle (see Holmström and Roberts, 1998) of why nonintegrated firms are observed to make large specific investments. In the networks we analyze, buyers invest in multiple assets specific to different, independent sellers. These multiple links allow buyers to share the capacity of sellers. There is an underlying technological reason for these links and the way they are spread out among different sellers. We show further that ex post bargaining may balance payoffs in such a way that firms wish to undertake these investments. Under the competitive revenue rule, buyers always build links efficiently. In equilibrium, buyers share the capacity of sellers, and there is a savings in overall investment costs.

The analysis has implications for evaluating "real-world" supply relations. If an industry is organized as a network, our results indicate that a network must be the efficient industrial structure. (If vertical integration were the efficient structure, networks would not be an equilibrium.) The network structure we observe may not be the first-best structure, but it does yield greater welfare than vertical integration. On the other hand, if an industry is vertically integrated, vertical integration is not necessarily the efficient structure. A network structure may be efficient but does not emerge because of distorted investment incentives or simple coordination failure.

This study also yields several predictions about differences in supply structures across industries. First, when investments in quasi-specific productive assets are relatively inexpensive, an industry is more likely to have a vertically integrated structure. 
Second, for intermediate costs of quasi-specific assets, an industry is more likely to have a network structure. This will be especially true when the links to sellers-communication, training, etc.-are not prohibitively expensive. ${ }^{61}$ Finally, the use of standardized inputs may be an indication of prohibitively high costs of quasi-specific productive capacity for specialized inputs.

The analysis indicates that observed differences in supply structures may be due to differences in firm-specific shocks. Case studies show that, over time, changes in demand uncertainty may affect supply arrangements. Helper, MacDuffie, and Sabel (forthcoming) argue that starting in the late 1920s, there was an increase in uncertainty in the U.S. automobile industry because of competition from the emerging used-car market and new independent manufacturers. The big automakers GM and Ford moved away from vertical integration to flexible, collaborative arrangements with independent suppliers. This trend to disintegration lasted through World War II, then reversed. ${ }^{62}$ Similarly, Storper (1989) holds that volatility in the demand for Hollywood movies increased in the late 1940s with the advent of television, leading to a replacement of the vertically integrated studio system with outsourcing for many aspects of a film's production. ${ }^{63}$ These studies suggest that disintegrated supply structures are a response to underlying environmental uncertainty.

Our analysis finds that high firm-specific demand shocks should be associated with a more network-like industrial structure. Greater dispersions of these shocks should be associated with a more connected network structure. Finally, aggregate or industrywide demand shocks may not be related to these differences in industrial structures, unless they affect the distributions of firm-specific shocks.

\section{Appendix}

- This Appendix contains proofs not contained in the text, and the full welfare comparison of industrial structures for a four-buyer industry.

We will assume throughout our proofs that the valuations $\mathbf{v}$ are generic, where by generic we mean that no two buyers have the same valuation and no buyer has a valuation of zero. This assumption simplifies our analysis. It is without loss of generality because our results depend only on the expectation of valuations, and nongeneric valuations occur with probability zero.

Proof of Proposition 1. Suppose $\bar{B} \geq 2$ and $\sigma>0$. Consider the network structure $\mathcal{N}$ where each buyer has a link to one seller, and this seller invests in a flexible asset. We have $W(\mathcal{N})=\bar{z}+\mu^{1 \cdot \bar{B}}(\sigma)-\bar{B} c-\alpha$.

Consider the set of investment $\operatorname{costs}(c, \alpha)$ where $\mathcal{N}$ yields (weakly) greater welfare than any nonnetwork structure. Let $\theta(\mathcal{N}, \sigma)$ denote these costs. For $\alpha \leq \bar{z}, \mathcal{V}$ yields (weakly) the highest welfare of all nonnetwork structures, and for $\alpha \geq \bar{z}, X$ yields (weakly) the highest welfare of all nonnetwork structures. Therefore, the region $\theta(\mathcal{N}, \sigma)$ is the set of all investment costs $(c, \alpha)$, where $W(\mathcal{N}) \geq W(\mathcal{V})=\bar{B}(\bar{z}-\alpha)$ and $W(\mathcal{N}) \geq W(X)=0$.

We show that the pair $\left(c_{o}, \alpha_{o}\right)=\left([1 / 2 \bar{B}] \mu^{1: \bar{B}}(\sigma), \bar{z}\right)$ is in $\theta(\mathcal{N}, \sigma)$. At $\left(c_{o}, \alpha_{o}\right), W(\mathcal{N})=(1 / 2 \bar{B}) \mu^{1: \bar{B}}(\sigma)$. For any $\sigma>0$, the order statistic $\mu^{1-\bar{B}}$ is strictly positive for $\bar{B} \geq 2$. (This follows from the fact that for any distribution with mean $0, \sum_{i=1}^{\bar{B}} \mu^{i: \bar{B}}=\mu^{1: 1}=0$. For any such distribution where an outcome other than zero occurs with positive probability, $\mu^{i \cdot \bar{B}}>0>\mu^{j \cdot \bar{B}}$ for some $i<j$.) Therefore, at $\left(c_{o}, \alpha_{o}\right), W(\mathcal{N})>0$. Since $\alpha_{o}=\bar{z}$, at this point $W(\mathcal{V})=0$. It follows trivially that the differences $W(\mathcal{N})-W(\mathcal{V})$ and $W(\mathcal{N})-W(X)$ are strictly positive at $\left(c_{o}, \alpha_{o}\right)$.

By continuity, $W(\mathcal{N})-W(\mathcal{V})$ and $W(\mathcal{N})-W(X)$ are strictly positive for an open neighborhood of $\left(c_{o}, \alpha_{o}\right)$ in the positive orthant of $\mathbb{R}^{2}$. That is, $\theta(\mathcal{N}, \sigma)$ contains an open set.

Finally, we note that $\theta(\mathcal{N}, \sigma) \subseteq \Theta(\sigma)$, since for all $(c, \alpha) \in \theta(\mathcal{N}, \sigma), \mathcal{N}$ yields greater welfare than any nonnetwork structure. Q.E.D.

${ }^{61}$ A related point is that reductions in the costs of links, such as enhancements in communication technologies, should increase the comparative advantage of networks.

${ }^{62}$ The move toward vertical integration after World War II and toward networks in the 1980 s is explained similarly. In the postwar expansion, the automakers were more concerned with market expansion than with innovation. This concern reversed in the 1980 s with the increase of foreign competition.

${ }^{63}$ See also Faulkner and Anderson (1987) and Aksoy and Robins (1992). 
Proof of Lemma 1. First, we note that for a network, the same number of sellers sells a good in each efficient allocation for each realization $\mathbf{v}$ of buyers' valuations. The proof of this result is available from the authors upon request. We denote this number of sellers as $\tilde{S}$.

We show here that for a network $\mathcal{N}$ with $B$ buyers and $S$ sellers, $E_{\mathbf{v}}\left[w\left(\mathbf{v}, A^{*}(\mathbf{v}, \mathcal{N})\right)\right]$ can be written as $\tilde{S} \bar{z}+\sum_{i=1}^{B} \beta_{i} \mu^{i \cdot B}$, where $\sum_{i=1}^{B} \beta_{i} \mu^{i: B} \geq 0$. The set of buyers that obtain goods in $A^{*}(\mathbf{v}, \mathcal{G})$ is determined only by the ordering of buyers' idiosyncratic shocks, not on the absolute levels of these shocks or the realization of the aggregate shock. Recall that $v_{i}=z+\epsilon_{i}$, where $z$ is the aggregate shock and $\epsilon_{i}$ is the idiosyncratic shock. There are $B$ ! orderings of buyers' idiosyncratic shocks, which we refer to as $o=1, \ldots, B$ !. For each ordering, we refer to an associated efficient allocation as $A^{* *}(o, \mathcal{G})$. For a generic valuation $\mathbf{v}$, the set of buyers that obtains goods in $A^{* *}(o, \mathcal{G})$ is unique. That is, although there may be several allocations that are efficient given the ordering $o$, the same set of buyers always obtains a good (for proof, see Kranton and Minehart (forthcoming (b))). For an ordering $o$, we define $\delta_{o}$ to be one if buyer $i$ obtains a good and zero if buyer $i$ does not obtain a good. The expected surplus of $A^{* *}(o, G)$ is the sum of the expected valuations of the buyers that obtain goods, conditional on the ordering $o$.

Since the idiosyncratic and aggregate shocks are independently distributed and exactly $\tilde{S}$ sellers sell in any efficient allocation, we can write the conditional expected welfare of $A^{* *}(o, \mathcal{G})$ for a given ordering $o$ as

$$
E_{\mathrm{v}}\left[w\left(\mathbf{v}, A^{* *}(o, \mathcal{N}()) \mid o\right]=\tilde{S} \bar{z}+E_{\epsilon}\left[\left(\sum_{i=1}^{B} \delta_{o}^{i} \epsilon_{i}\right) \mid o\right],\right.
$$

where the expectation on the left-hand side is taken both over the aggregate and idiosyncratic shocks conditional on the ordering $o$, and the expectation on the right-hand side is taken over the idiosyncratic shocks conditional on the ordering $o$. Since each ordering $o$ occurs with probability $1 / B$ !, we have

$$
E_{\mathbf{v}}\left[w\left(\mathbf{v}, A^{*}(\mathbf{v}, \mathcal{N})\right)\right]=\tilde{S} \bar{z}+\sum_{o=1}^{B !} \frac{1}{B !} E_{\epsilon}\left[\left(\sum_{i=1}^{B} \delta_{o}^{i} \epsilon_{i}\right) \mid o\right] .
$$

By linearity of the expectation operator (and recalling that $\delta_{o}^{i}$ is a constant for fixed $i$ and $o$ ), we can write this as

$$
E_{\mathbf{v}}\left[w\left(\mathbf{v}, A^{*}(\mathbf{v}, \mathcal{N})\right)\right]=\tilde{S} \bar{z}+\sum_{o=1}^{B !} \sum_{i=1}^{B} \frac{\delta_{o}^{i}}{B !} E_{\epsilon}\left[\epsilon_{i} \mid o\right] .
$$

We now argue that we can express $E_{\mathbf{v}}\left[w\left(\mathbf{v}, A^{*}(\mathbf{v}, \mathcal{N})\right]\right.$ in terms of the order statistics of the distribution of $G \sigma$. Specifically, we argue that each term $E_{e}\left[\epsilon_{i} \mid o\right]$ is an expectation of an order statistic. To see this, consider an ordering $o$. Let $p(i \mid o)$ be the position of buyer $i$ in ordering $o$; that is, if in ordering $o$, buyer $i$ has the $j$ th-highest valuation, then $p(i \mid o)=j$. We show in Claim Al below that

$$
E_{\epsilon}\left[\epsilon_{i} \mid o\right]=\mu^{p(i \mid o): B} .
$$

Hence, we can rewrite the second term above as follows:

$$
\sum_{o=1}^{B !} \sum_{i=1}^{B} \frac{\delta_{o}^{i}}{B !} E_{\epsilon}\left[\epsilon_{i} \mid o\right]=\sum_{o=1}^{B !} \sum_{i=1}^{B} \frac{\delta_{o}^{t}}{B !} \mu^{p(i \mid o): B} .
$$

Whenever an order statistic occurs in the above summation, it is with the coefficient $1 / B$ !. Combining order statistics of the same rank, we write

$$
\sum_{o=1}^{B !} \sum_{i=1}^{B} \frac{\delta_{o}^{i}}{B !} E_{\epsilon}\left[\epsilon_{i} \mid o\right]=\sum_{i=1}^{B} \beta_{i} \mu^{i: B}
$$

where the $\beta_{i}$ are positive constants. That is,

$$
E_{\mathbf{v}}\left[w\left(\mathbf{v}, A^{*}(\mathbf{v}, \mathcal{N})\right)\right]=\tilde{S} \bar{z}+\sum_{i=1}^{B} \beta_{i} \mu^{i: B} .
$$

We finish by showing that $\sum_{i=1}^{B} \beta_{i} \mu^{i: B} \geq 0$. Fix any allocation $A$ in which $\tilde{S}$ buyers obtain goods. The 
expected welfare $E_{\mathbf{v}}[w(\mathbf{v}, A)]$ for this allocation is simply $\tilde{S} \bar{z}$. The maximal expected welfare $E_{\mathrm{v}}\left[w\left(\mathbf{v}, A^{*}(\mathbf{v}, \mathcal{N})\right)\right]$ must be weakly greater than $\tilde{S} \bar{z}$. That is, $\sum_{i=1}^{B} \beta_{i} \mu^{i: B} \geq 0$. Q.E.D.

Claim A1. $E_{\epsilon}\left[\epsilon_{i} \mid o\right]=\mu^{p(i \mid o): B}$.

Proof. We first describe an alternative way to express $\mu^{j: B}$. In most of the article, we use the expression

$$
\mu^{j: B}=B\left(\begin{array}{l}
B-1 \\
B-j
\end{array}\right) \int_{0}^{\infty}[G(\epsilon)]^{B-j}[1-G(\epsilon)]^{j-1} g(\epsilon) \epsilon d \epsilon .
$$

This is a useful and commonly used formula (see David, 1989). A second way to express $\mu^{j: B}$, however, is as the sum over all orderings of the expectation of the $j$ th-highest shock in each ordering. Because the shocks are identically and independently distributed, the expectation of the $j$ th-highest shock in each ordering is independent of the ordering. We may write it simply as $I_{j: B}$. (That is, we do not need to write $I_{j: B}(o)$ for each ordering $o$.) There are $B$ ! orderings, which gives the expression

$$
\mu^{j: B}=(B !) I_{j: B} .
$$

To prove the claim, we note that $E_{e}\left[\epsilon_{i} \mid o\right]$ for a buyer $i$ with the $j$ th-highest shock in $o$ (that is, $p(i \mid o)=j)$ is the expectation of the $j$ th-highest shock conditional on the ordering $o$. The probability of $o$ is $1 / B$ !, so the conditional expectation is

$$
E_{\epsilon}\left[\epsilon_{i} \mid o\right]=\left(\frac{1}{B !}\right)^{-1} I_{j: B}=(B !) I_{j: B}=\mu^{j: B} .
$$

Proof of Proposition 2. (i) This result follows directly from Lemma 1 and the fact that $\mu^{i: B}(\sigma)$ for all $i$ is homogeneous of degree one in $\sigma$.

(ii) We first show weak inclusion: $\Theta(\sigma) \subseteq \Theta(\tilde{\sigma})$. For each network structure $\mathcal{N}$, let $\theta(\mathcal{N}, \sigma)$ denote the region where $\mathcal{N}$ yields greater welfare than any nonnetwork structure. (This region could be empty for some networks.) Denote the union of all these regions by $U(\sigma)$. Note that $U(\sigma)=\Theta(\sigma)$, the region where a network structure is efficient. To see this, note that for any point $(c, \alpha) \in U(\sigma)$, some network yields greater welfare than all nonnetwork structures, so a network structure is efficient for this $(c, \alpha)$. For any point $(c, \alpha) \notin U(\sigma)$, no network structure yields greater welfare than a nonnetwork structure (since we have considered all network structures). Now consider some $\tilde{\sigma}>\sigma$ and a network structure $\mathcal{N}$. When $\sigma$ increases, the welfare of a network structure (weakly) increases, but the welfare of nonnetwork structures remains fixed. Therefore, $\theta(\mathcal{N}, \sigma) \subseteq \theta(\mathcal{N}, \tilde{\sigma})$. Because $\Theta(\tilde{\sigma})$ is the union of the regions $\theta(\mathcal{N}, \tilde{\sigma})$, we have shown that $\Theta(\sigma) \subseteq \Theta(\tilde{\sigma})$.

We next show strict inclusion: $\Theta(\sigma) \subset \Theta(\tilde{\sigma})$. Let $\mathcal{N}$ be an efficient network. Then in the expression $W(\mathcal{N})=\tilde{S}(\bar{z}-\alpha)+\sum_{i=1}^{B} \beta_{i} \mu^{i: B}(\sigma)-k c$ from Lemma 1, we have $\sum_{i=1}^{B} \beta_{i} \mu^{i: B}(\sigma)>0$. To see this, suppose that the statement is not true. Then by Lemma $1, \sum_{i=1}^{B} \beta_{i} \mu^{i: B}(\sigma)=0$. Consider an industrial structure where $\tilde{S}$ buyers are vertically integrated and the other buyers do not invest. This yields welfare $\tilde{S}(\bar{z}-\alpha)$. If $\bar{z}>\alpha$, then this industrial structure yields strictly higher welfare than $W(\mathcal{N})=\tilde{S}(\bar{z}-\alpha)-k c$ because $c>0$ and $k \geq 1$. This contradicts the efficiency of $\mathcal{N}$. If $\bar{z} \leq \alpha$, then no investment $\mathcal{X}$ yields a welfare of zero, which is strictly higher than $W(\mathcal{N})$ because $W(\mathcal{N}) \leq-k c<0$. This again contradicts the efficiency of $\mathcal{N}$.

Next, consider any point $(c, \alpha)$ on the boundary between the set $\Theta(\sigma)$ and the set where no investment, $X$, is efficient. To see that such a point exists, recall from the proof of Proposition 1 that $\Theta(\sigma)$ contains the point $\left(c_{o}, \alpha_{o}\right)=\left([1 / 2 \bar{B}] \mu^{1: \bar{B}}(\sigma), \bar{z}\right)$. For any $c, X$ is the only efficient structure when $\alpha$ is sufficiently large. It follows that there is some $\tilde{\alpha}$ such that $\left(c_{o}, \tilde{\alpha}\right)$ is on the boundary between $\Theta(\sigma)$ and the set where noinvestment $X$ is efficient.

Let $\mathcal{N}$ be an efficient network for this boundary point $\left(c_{o}, \tilde{\alpha}\right)$. We have

$$
W(\mathcal{N})=\tilde{S}(\bar{z}-\alpha)+\sum_{i=1}^{B} \beta_{i} \mu^{i: B}(\sigma)-k c
$$

where $\sum_{i=1}^{B} \beta_{i} \mu^{i \cdot B}(\sigma)>0$. With order statistics homogenous of degree one in $\sigma$, we can write $\mu^{i \cdot B}(\sigma)=\sigma \mu^{i \cdot B}(1)$ and express this summation as $\sigma \sum_{i=1}^{B} \beta_{i} \mu^{i: B}(1)>0$.

Since $\mathcal{N}$ is on the boundary between $\Theta(\sigma)$ and the region where $\mathcal{X}$ is efficient, 


$$
W(\mathcal{N})=0=\tilde{S}(\bar{z}-\alpha)+\sigma \sum_{i=1}^{B} \beta_{i} \mu^{i: B}(1)-k c .
$$

Since $\sigma \sum_{i=1}^{B} \beta_{i} \mu^{i: B}(1)>0, W(\mathcal{N})$ is strictly increasing in $\sigma$. We conclude that for any $\tilde{\sigma}>\sigma, W(\mathcal{N})>0$ at $(c, \alpha)$. It follows that the set $\theta(\mathcal{N}, \tilde{\sigma})$ contains on open neighborhood of $\left(c_{o}, \tilde{\alpha}\right)$. This neighborhood is therefore in $\Theta(\tilde{\sigma})$ and contains an (open) set of pairs $(c, \alpha)$ that were not in $\Theta(\sigma)$. We have already proved that $\Theta(\sigma) \subseteq \Theta(\tilde{\sigma})$. We have now shown that the inclusion is strict. Q.E.D.

Proof of Proposition 3. Let $\mathcal{N}$ denote the original network and let $\mathcal{N}{ }^{\prime}$ denote a subgraph of $\mathcal{N}$. Let $S$ be the number of sellers in the two networks and $B$ the number of buyers. As discussed in the proof of Lemma 1 , for a fixed network, the number of sellers that sells goods in any efficient allocation is the same. By assumption, this number $\tilde{S} \leq S$ is the same in both networks $\mathcal{N}$ and $\mathcal{N}^{\prime}$.

By Lemma $1, W(\mathcal{N})$ can be written as $\tilde{S} \bar{z}+\sum_{i=1}^{B} \beta_{i} \mu^{i: B}-S \alpha-k c$, where $k$ is the number of links. $W\left(\mathcal{N}^{\prime}\right)$ can be written as $\tilde{S} \bar{z}+\sum_{i=1}^{B} \rho_{i} \mu^{i: B}-S \alpha-k^{\prime} c$, where $k^{\prime}$ is the number of links and $k^{\prime}<k$. The difference in welfare is then

$$
\sum_{i=1}^{B}\left(\beta_{i}-\rho_{i}\right) \mu^{i: B}-\left(k-k^{\prime}\right) c .
$$

The first term above, $\sum_{i=1}^{B}\left(\beta_{i}-\rho_{i}\right) \mu^{i: B}$, is the difference in expected gains from trade in the two networks. That is, $\sum_{i=1}^{B}\left(\beta_{i}-\rho_{i}\right) \mu^{i: B}=E_{\mathbf{v}}\left[w\left(\mathbf{v}, A^{*}(\mathbf{v}, \mathcal{N})\right)\right]-E_{\mathbf{v}}\left[w\left(\mathbf{v}, A^{*}\left(\mathbf{v}, \mathcal{N}^{\prime}\right)\right)\right]$. This difference is weakly positive. To see this, fix a valuation $\mathbf{v}$ and consider efficient allocations in each network, $A^{*}(\mathbf{v}, \mathcal{N})$ and $A^{*}\left(\mathbf{v}, \mathcal{N}{ }^{\prime}\right)$. The efficient allocation $A^{*}\left(\mathbf{v}, \mathcal{N}^{\prime}\right)$ is feasible in the more connected network $\mathcal{N}$, so it must be that $A^{*}(\mathbf{v}, \mathcal{N})$ yields weakly higher welfare. That is, the difference $w\left(\mathbf{v}, A^{*}(\mathbf{v}, \mathcal{N})\right)-w\left(\mathbf{v}, A^{*}\left(\mathbf{v}, \mathcal{N}^{\prime}\right)\right)$ is weakly positive. Taking the expectation over $\mathbf{v}$, we have that the difference

$$
E_{\mathbf{v}}\left[w\left(\mathbf{v}, A^{*}(\mathbf{v}, \mathcal{N})\right)\right]-E_{\mathbf{v}}\left[w\left(\mathbf{v}, A^{*}\left(\mathbf{v}, \mathcal{N}^{\prime}\right)\right)\right]=\sum_{i=1}^{B}\left(\beta_{i}-\rho_{i}\right) \mu^{i: B}(\sigma)
$$

is weakly positive.

Since the term $\left(k-k^{\prime}\right) c$ is constant and $\mu^{i: B}(\sigma)$ is homogenous of degree one in $\sigma, \sum_{i=1}^{B}\left(\beta_{i}-\rho_{i}\right) \mu^{i: B}$ is increasing in $\sigma$, we have our result. Q.E.D.

\section{ㅁ Boundaries of regions in Figure 4.}

For $W\left(\mathcal{N}_{1}\right)=W(X)=0$, we have $\alpha+3 c=\bar{z}+1 / 2\left[\mu^{1: 4}+\mu^{2: 4}\right]-3 c$.

For $W\left(\mathcal{N}_{1}\right)=W\left(\mathcal{N}_{2}\right)$, we have from the text $c=1 / 6\left(\mu^{2: 4}-\mu^{3: 4}\right)$.

For $W\left(\mathcal{N}_{1}\right)=W(\mathcal{V})$, we have from the text $\alpha-3 c=\bar{z}-1 / 2\left[\mu^{1: 4}+\mu^{2: 4}\right]$.

For $W\left(\mathcal{N}_{2}\right)=W(\mathcal{V})$, we have $\alpha-2 c=\bar{z}-\left[1 / 2 \mu^{1: 4}+1 / 3 \mu^{2: 4}+1 / 6 \mu^{3: 4}\right]$.

For $W\left(\mathcal{N}_{2}\right)=W(X)=0$, we have $\alpha+2 c=\bar{z}+\left[1 / 2 \mu^{1: 4}+1 / 3 \mu^{2: 4}+1 / 6 \mu^{3: 4}\right]$.

$\square \quad$ The efficient industrial structures for a four-buyer industry. Here we show the efficient industrial structures for a four-buyer industry. We consider structures with four buyers and any number of sellers. When $\epsilon_{i}$ is symmetric around zero, ${ }^{64}$ the only network industrial structures that are ever efficient are $X, \mathcal{V}, \mathcal{N}_{1}$, and $\mathcal{N}_{2}$, presented in Figure 2, and the structures $\mathcal{N}_{3}, \mathcal{N}_{4}, \mathcal{N}_{5}$, and $\mathcal{N}_{6}$ presented in Figure A1.

To prove that these structures are the efficient network industrial structures, we determine the welfare for each possible structure for four buyers and compare them. The full set of comparisons is available from the authors on request. We provide one example here. Consider a network structure $\mathcal{K}_{1}^{\prime}$ that is obtained from $\mathcal{N}_{1}$ by removing the link between $b_{3}$ and $s_{1}$. In this network, the two goods can be allocated to any pair except $\left\{b_{3}, b_{4}\right\}$. For orderings of buyers' valuations where $b_{3}$ and $b_{4}$ have the top two valuations, whichever has the lower valuation does not obtain a good in the efficient allocation. Instead, the buyer with the thirdhighest valuation in the ordering (either $b_{1}$ or $b_{2}$ ) obtains a good. There are four such orderings (out of 24 orderings), so the probability of such an ordering is $1 / 6$. The welfare of this structure is then

$$
W\left(\mathcal{N}_{1}^{\prime}\right)=2 \bar{z}+\mu^{1: 4}+\frac{5}{6} \mu^{2: 4}+\frac{1}{6} \mu^{3: 4}-5 c-2 \alpha .
$$

${ }^{64}$ The symmetry assumption is used to pin down one welfare comparison. 


\section{FIGURE A1}

OTHER EFFICIENT NETWORK STRUCTURES FOR A FOUR-BUYER INDUSTRY

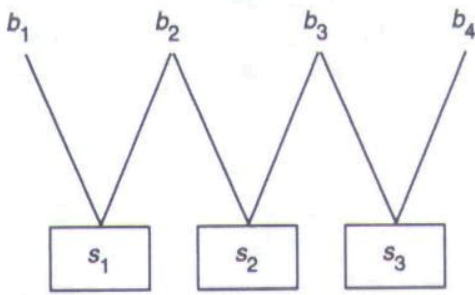

$N_{3}$

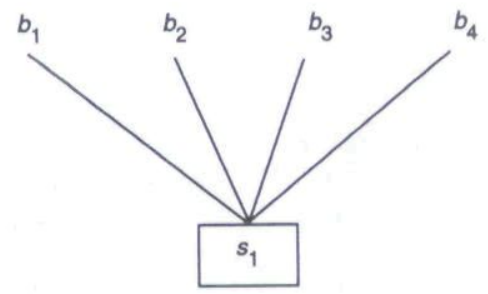

$\mathscr{N}_{5}$

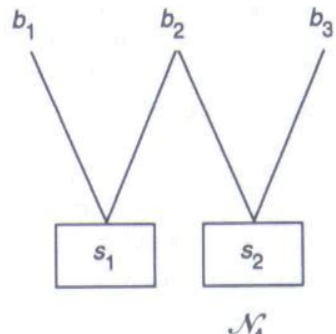

$\mathscr{N}_{4}$

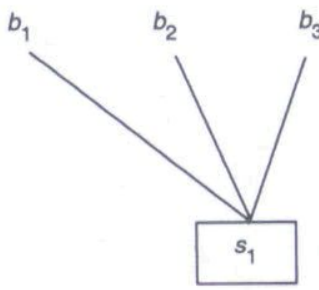

$\mathscr{N}_{6}$

The welfare of $\mathcal{N}_{1}$ is

$$
W\left(\mathcal{K}_{1}\right)=2 \bar{z}+\mu^{1: 4}+\mu^{2: 4}-6 c-2 \alpha .
$$

Comparing these, we have $W\left(\mathcal{N}_{1}\right) \geq W\left(\mathcal{N}_{1}^{\prime}\right)$ when

$$
\frac{1}{6}\left[\mu^{2: 4}-\mu^{3: 4}\right] \geq c .
$$

On the other hand, the welfare of the network $\mathcal{N}_{2}$ is

$$
W\left(\mathcal{N}_{2}\right)=2 \bar{z}+\mu^{1: 4}+\frac{2}{3} \mu^{2: 4}+\frac{1}{3} \mu^{3: 4}-4 c-2 \alpha .
$$

We have $W\left(\mathcal{N}_{2}\right) \geq W\left(\mathcal{N}_{1}^{\prime}\right)$ when

$$
\frac{1}{6}\left[\mu^{2: 4}-\mu^{3: 4}\right] \leq c .
$$

Therefore, for all link costs, $\mathcal{N}_{1}^{\prime}$ has lower welfare than one of the networks $\mathcal{N}_{1}$ and $\mathcal{N}_{2}$, and $\mathcal{N}_{1}^{\prime}$ is never efficient.

Figure A2 shows schematically when each structure is efficient, as a function of $c$ and $\alpha$ for a given $\sigma$. The boundaries of each region are derived from the welfare of each structure, as in Figure 4.

Proof of Proposition 7. Suppose $\sigma>0$ and $\bar{B} \geq 3$. Consider a network structure where all buyers invest in one link to one specialized seller that invests in a flexible asset. Let $\Omega$ denote the region of investment costs $(c, \alpha)$ where this network is an equilibrium. We show that (i) this region is a simplex and (ii) for $\bar{B} \geq 3$ and any $\sigma>0, \Omega$ has positive measure. That is, there is an open set of costs $(c, \alpha)$ where $c>0$ and $\alpha>0$ such that the network is an equilibrium outcome for each $(c, \alpha)$ in the set.

(i) We derive $\Omega$ by examining the equilibrium conditions for this network industrial structure when payoffs are determined by the competitive revenue rule. 
FIGURE A2

INVESTMENT COSTS FOR EFFICIENT NETWORKS IN FOUR-BUYER INDUSTRY

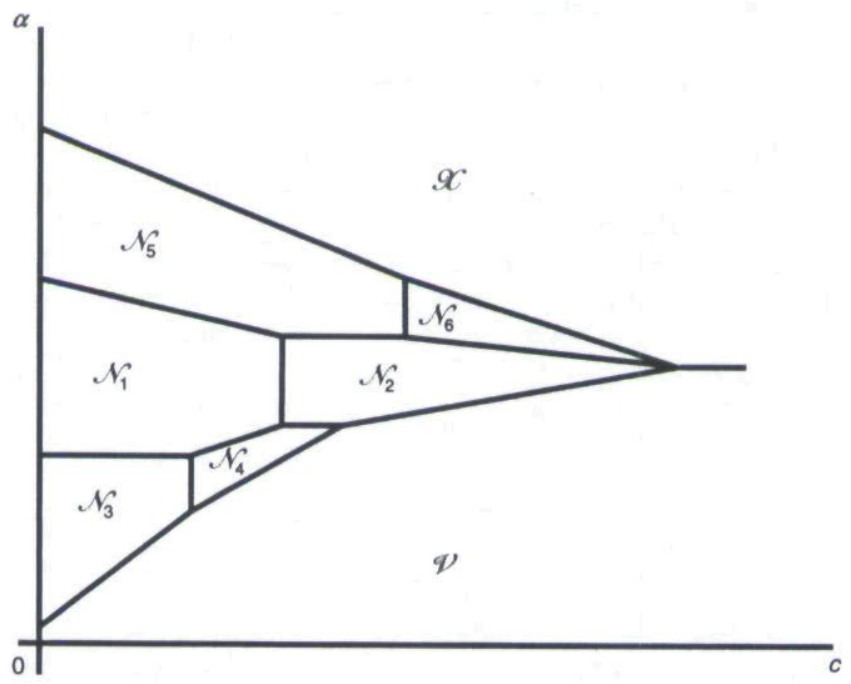

Since $\mu^{k \cdot \bar{B}}(\sigma)$ is homogeneous of degree one in $\sigma$, we will write (with some abuse of notation) $\mu^{k \cdot \bar{B}}(\sigma)$ as $\sigma \mu^{k \cdot \bar{B}}$. Each buyer's payoff in this network is $(\sigma / \bar{B})\left[\mu^{1: \bar{B}}-\mu^{2: \bar{B}}\right]-c$. To see this, note that a buyer obtains a good when it has the highest valuation. In this case, its marginal contribution is the difference between its valuation and the second-highest valuation. The expectation of this marginal contribution conditional on the ordering is $\sigma\left[\mu^{1 \cdot \bar{B}}-\mu^{2 \cdot \bar{B}}\right]$. (This follows from the proof of Lemma 1.) The probability of an ordering arising in which the buyer has the highest valuation is $1 / \bar{B}$.

Let us consider a buyer's equilibrium conditions. A buyer must prefer investing in the link to not investing:

$$
\frac{\sigma}{\bar{B}}\left[\mu^{1: \bar{B}}-\mu^{2: \bar{B}}\right]-c \geq 0 .
$$

Second, a buyer must prefer investing in the link to vertical integration:

$$
\frac{\sigma}{\bar{B}}\left[\mu^{1: \bar{B}}-\mu^{2 \cdot \bar{B}}\right]-c \geq \bar{z}-\alpha .
$$

Finally, a buyer never wants to build a link to other sellers because none are investing in productive capacity. Setting the first condition as an equality, we have the vertical line:

$$
\bar{c}=\frac{\sigma}{\bar{B}}\left[\mu^{1: \bar{B}}-\mu^{2: \bar{B}}\right]
$$

Setting the second condition as an equality and rearranging, we have the following upward-sloping line in $(c, \alpha)$ space:

$$
\underline{\alpha}-c=\bar{z}-\frac{\sigma}{\bar{B}}\left[\mu^{1: \bar{B}}-\mu^{2: \bar{B}}\right] .
$$

Now consider the sellers' equilibrium conditions. No seller that is not investing will want to invest, since it has no links to buyers. The seller that does invest must earn positive profits. Under the competitive revenue rule, its equilibrium condition is $\bar{z}+\sigma \mu^{2: \bar{B}} \geq \alpha$. Setting this condition as an equality, we have the horizontal line: 


$$
\bar{\alpha}=\bar{z}+\sigma \mu^{2 \cdot \bar{B}} .
$$

The latter two lines intersect at the point $c_{0}=\sigma / \bar{B}\left[\mu^{1: \bar{B}}+(\bar{B}-1) \mu^{2 \cdot \bar{B}}\right]$ and $\alpha=\bar{z}+\sigma \mu^{2: \bar{B}}$. These three lines, the $\alpha$-axis, and the $c$-axis form a simplex, which we call $\Omega$.

(ii) We prove that $\Omega$ has positive measure. That is, we prove that there exists a nontrivial set of investment costs $c>0, \alpha>0$ such that buyers' and sellers' equilibrium conditions are both satisfied.

The upper edge of the simplex is the horizontal line $\bar{\alpha}=\bar{z}+\sigma \mu^{2: \bar{B}}$. The expression for $\bar{\alpha}$ is the expectation of the second-highest valuation in the group of buyers. It is strictly positive because given $\sigma>0$, it is strictly larger than the expectation of the third-highest valuation. The third-highest valuation is weakly positive by our assumption of nonnegative valuations.

If both $\bar{c}$ and $c_{0}$ are strictly positive, then the simplex has nonempty interior and hence positive measure. The cost $\bar{c}$ is strictly positive because $\mu^{1: \bar{B}}>\mu^{2: \bar{B}}$ when $\sigma>0$. For $c_{0}$, the triangle rule can be used to show the standard identity $\sum_{i=1}^{B}(1 / B) \mu^{i: B}=\mu$, where $\mu$ is the mean of the underlying distribution. Therefore, for a distribution with mean zero, $(1 / \bar{B}) \mu^{1: \bar{B}}=-(1 / \bar{B}) \sum_{i=2}^{\bar{B}} \mu^{i: \bar{B}}$. Substituting for $(1 / \bar{B}) \mu^{1: \bar{B}}$ gives us the expression $c_{0}=(\sigma / \bar{B})\left[(\bar{B}-1) \mu^{2: \bar{B}}-\sum_{i=2}^{\bar{B}} \mu^{i: \bar{B}}\right]$. Since $\mu^{2: \bar{B}}>\mu^{i \cdot \bar{B}}$ for $i \geq 3$ when $\sigma>0$, we have

$$
[(\bar{B}-1) / \bar{B}] \mu^{2: \bar{B}}-\sum_{i=2}^{\bar{B}}(1 / \bar{B}) \mu^{i \cdot \bar{B}}>0 .
$$

The next proposition shows that a network equilibrium can exist for sufficiently large dispersion in buyers' idiosyncratic shocks under the Shapley value revenue rule. We say a dispersion $\sigma$ is feasible if a buyer's valuation $v_{i}=z+\epsilon_{i}$ is weakly positive for all realizations of the aggregate and idiosyncratic shocks.

Proposition A1. With the Shapley value, for $\sigma$ sufficiently high, there is a region of investment $\operatorname{costs} \Psi$ such that if $\sigma$ is feasible, then a network industrial structure is an equilibrium for all $(c, \alpha) \in \Psi$.

Proof. Suppose $\sigma>0$ and $\bar{B} \geq 3$. Consider a network structure where all $\bar{B}$ buyers invest in one link to one specialized seller that invests in a flexible asset. Let $\Psi$ denote the region of investment $\operatorname{costs}(c, \alpha)$ where this structure is an equilibrium under Shapley revenues. We show that (i) this region is a simplex and (ii) for $\sigma$ sufficiently high, $\Psi$ has positive measure.

(i) We derive $\Psi$ from the equilibrium conditions for this network industrial structure.

With the Shapley revenue rule, each buyer's revenues derive from its contribution to coalitions of size $n=1 \cdots \bar{B}$. Revenues are a weighted sum of an agent's contribution to different coalitions. The weight placed on a coalition of size $n$ in this network with $\bar{B}+1$ agents is $[n !(\bar{B}-n) !] /(\bar{B}+1) !$. The only coalitions to which a buyer would add surplus are coalitions that include the seller. From all the $n$-size coalitions, there are only $\left(\begin{array}{c}\bar{B}-1 \\ n-1\end{array}\right)$ such coalitions. These coalitions consist of $n-1$ buyers and one seller. For $n=1$, the contribution is $\bar{z}$. For $n \geq 2$, a buyer's contribution is $\sigma\left[\mu^{1: n}-\mu^{1: n-1}\right]$. By the triangle rule, this contribution is $(\sigma / n)\left[\mu^{1: n}-\mu^{2: n}\right]$.

Let us consider a buyer's equilibrium conditions. A buyer must prefer investing in the link to not investing:

$$
\frac{1 !(\bar{B}-1) !}{(\bar{B}+1) !} \bar{z}+\sum_{n=2}^{\bar{B}} \frac{n !(\bar{B}-n) !}{(\bar{B}+1) !}\left(\begin{array}{l}
\bar{B}-1 \\
n-1
\end{array}\right) \frac{\sigma}{n}\left[\mu^{1: n}-\mu^{2: n}\right]-c \geq 0
$$

Second, a buyer must prefer investing in the link to vertical integration:

$$
\frac{1 !(\bar{B}-1) !}{(\bar{B}+1) !} \bar{z}+\sum_{n=2}^{\bar{B}} \frac{n !(\bar{B}-n) !}{(\bar{B}+1) !}\left(\begin{array}{l}
\bar{B}-1 \\
n-1
\end{array}\right) \frac{\sigma}{n}\left[\mu^{1: n}-\mu^{2 \cdot n}\right]-c \geq \bar{z}-\alpha .
$$

Finally, a buyer never wants to build a link to other sellers because none are investing in productive capacity. Setting the first condition as an equality, we have the vertical line:

$$
\frac{1 !(\bar{B}-1) !}{(\bar{B}+1) !} \bar{z}+\sum_{n=2}^{\bar{B}} \frac{n !(\bar{B}-n) !}{(\bar{B}+1) !}\left(\begin{array}{c}
\bar{B}-1 \\
n-1
\end{array}\right) \frac{\sigma}{n}\left[\mu^{1: n}-\mu^{2: n}\right]=\bar{c} .
$$

Setting the second condition as an equality and simplifying gives us the upward-sloping line in $(c, \alpha)$ space: 


$$
\underline{\alpha}-c=\bar{z}\left[1-\frac{1}{(\bar{B}+1) \bar{B}}\right]-\frac{\sigma}{(\bar{B}+1) \bar{B}} \sum_{n=2}^{\bar{B}}\left[\mu^{1: n}-\mu^{2: n}\right] .
$$

Now consider the sellers' equilibrium conditions. No seller that is not investing will want to invest, since it has no links to buyers. The seller that does invest must earn positive profits. Under the Shapley value, the seller's revenues derive from its contribution to coalitions of buyers. For a coalition of size $n$, a seller contributes $\bar{z}+\sigma \mu^{1: n}$, and there are $\left(\begin{array}{c}\bar{B} \\ n\end{array}\right)$ such $n$-size coalitions. The equilibrium condition for the seller is then

$$
\sum_{n=1}^{\bar{B}} \frac{n !(\bar{B}-n) !}{(\bar{B}+1) !}\left(\begin{array}{l}
\bar{B} \\
n
\end{array}\right)\left[\bar{z}+\sigma \mu^{1: n}\right] \geq \alpha
$$

Setting this as an equality and simplifying, we have the horizontal line:

$$
\bar{\alpha}=\frac{\bar{B}}{\bar{B}+1} \bar{z}+\frac{\sigma}{(\bar{B}+1)} \sum_{n=2}^{\bar{B}} \mu^{1: n}
$$

(since $\mu^{1: 1}=0$ ). The latter two lines intersect at

$$
c_{0}=\frac{1-\bar{B}}{\bar{B}} \bar{z}+\sigma\left[\sum_{n=2}^{\bar{B}} \mu^{1: n}+\frac{1}{\bar{B}} \sum_{n=2}^{\bar{B}}\left[\mu^{1: n}-\mu^{2: n}\right]\right] \text { and } \quad \bar{\alpha}=\frac{\bar{B}}{\bar{B}+1} \bar{z}+\frac{\sigma}{(\bar{B}+1)} \sum_{n=2}^{\bar{B}} \mu^{1: n}>0,
$$

where the last strict inequality follows because $\sigma>0$ and the expectation of the highest-order statistic in a group of buyers of size $n$ is strictly positive. These three lines, the $\alpha$-axis, and the $c$-axis form a simplex, which we call $\Psi$.

(ii) We prove that $\Psi$ has positive measure. That is, we prove that there exists a nontrivial set of investment costs $c>0, \alpha>0$ such that buyers' and sellers' equilibrium conditions are both satisfied.

The upper edge of the simplex is the horizontal line $\bar{\alpha}$. We already argued that $\bar{\alpha}>0$. If both $\bar{c}$ and $c_{0}$ are strictly positive, then the simplex $\Psi$ has nonempty interior and hence positive measure. For $\bar{c}$, this follows from the fact that $\sigma>0$ and $\mu^{1: n}>\mu^{2: n}$. To show that $c_{0}$ is strictly positive, we must show that

$$
\sigma\left[\sum_{n=2}^{\bar{B}} \mu^{1: n}+\frac{1}{\bar{B}} \sum_{n=2}^{\bar{B}}\left[\mu^{1: n}-\mu^{2: n}\right]\right]>\frac{\bar{B}-1}{\bar{B}} \bar{z} .
$$

Since $\mu^{1: n}>0,\left[\mu^{1: n}-\mu^{2: n}\right]>0$, and $[(\bar{B}-1) / \bar{B}]<1$, this inequality is satisfied for $\sigma$ sufficiently high. If we can take $\sigma$ to be this high without violating our assumption that buyers' valuations are nonnegative, then a network equilibrium exists for $\sigma$. Q.E.D.

We show that the assumptions of Proposition Al can be satisfied for some distributions by providing an example.

Example A1. Suppose the aggregate shock is equal to $\bar{z}$ with probability one. Each buyer $i$ 's idiosyncratic shock $\epsilon_{i}$ is identically, independently, and uniformly distributed on $[-\sigma \bar{z}, \sigma \bar{z}]$, where $\sigma \in[0,1]$. The expectation of the $k$ th-order statistic of the idiosyncratic shock is then $\mu^{k: \bar{B}}=\sigma \bar{z}[1-(2 k /(\bar{B}+1))]$. The above existence condition for the Shapley value is

$$
\sigma \bar{z}\left\{\sum_{n=2}^{\bar{B}}\left(1-\frac{2}{n+1}\right)+\frac{1}{\bar{B}} \sum_{n=2}^{\bar{B}}\left[\left(1-\frac{2}{n+1}\right)-\left(1-\frac{4}{n+1}\right)\right]\right\}>\frac{\bar{B}-1}{\bar{B}} \bar{z},
$$

which simplifies to

$$
\sigma \sum_{n=2}^{\bar{B}}\left[1-\left(\frac{\bar{B}-1}{\bar{B}}\right)\left(\frac{2}{n+1}\right)\right]>\frac{\bar{B}-1}{\bar{B}}
$$

The summation on the left-hand side, $\sum_{n=2}^{\bar{B}}\{1-[(\bar{B}-1) / \bar{B}](2 /(n+1))\}$, strictly exceeds $(\bar{B}-1) / \bar{B}$. To see this, set $n=2$, which gives us a lower bound on each term in the sum. We then check that 


$$
\left[1-\left(\frac{\bar{B}-1}{\bar{B}}\right)\left(\frac{2}{3}\right)\right]>\frac{1}{\bar{B}},
$$

which is satisfied for $\bar{B}>1$. Therefore, there exists some $\bar{\sigma}<1$ such that for all $1>\sigma \geq \bar{\sigma}$ the existence condition is satisfied.

\section{References}

ACEmoglu, D. “A Microfoundation for Social Increasing Returns in Human Capital Accumulation.” Quarterly Journal of Economics, Vol. 11 (1996), pp. 779-804.

AKsoy, A. AND RoBINS, K. "Hollywood for the 21st Century: Global Competition for Critical Mass in Image Markets." Cambridge Journal of Economics, Vol. 16 (1992), pp. 1-22.

Aumann, R.J. AND Myerson, R.B. "Endogenous Formation of Links between Players and Coalitions: An Application of the Shapley Value." In A. Roth, ed., The Shapley Value. Cambridge: Cambridge University Press, 1988.

Ausubel, L. "An Efficient Ascending-bid Auction for Multiple Objects." Working Paper no. 97-06, Department of Economics, University of Maryland, 1997.

Bala, V. And Goyal, S. “A Noncooperative Model of Network Formation." Econometrica, forthcoming.

BARON, D. "Demand Uncertainty in Imperfect Competition." International Economic Review, Vol. 12 (1971), pp. 196-208.

Bolton, P. AND Whinston, M.D. “Incomplete Contracts, Vertical Integration, and Supply Assurance.” Review of Economic Studies, Vol. 60 (1993), pp. 121-148.

Brusco, S. "The Emilian Model: Productive Decentralisation and Social Integration." Cambridge Journal of Economics, Vol. 6 (1982), pp. 167-184.

CARlton, D.W. "Market Behavior with Demand Uncertainty and Price Inflexibility." American Economic Review, Vol. 68 (1978), pp. 571-587.

- "Vertical Integration in Competitive Markets under Uncertainty." Journal of Industrial Economics, Vol. 27 (1979), pp. 189-209.

CAwthorne, P.M. "Of Networks and Markets: The Rise and Rise of a South Indian Town, the Example of Tiruppur's Cotton Knitwear Industry." World Development, Vol. 23 (1995), pp. 43-56.

DAvID, H.A. Order Statistics, 3d. ed. New York: Wiley, 1989.

Demange, G., Gale, D., and Sotomayor, M. "Multi-Item Auctions." Journal of Political Economy, Vol. 94 (1986), pp. 863-872.

Economides, N. and Himmelberg, C. "Critical Mass and Network Size with Application to the U.S. Fax Market." Working Paper no, EC-95-11, Department of Economics, Stern School of Business, New York University, 1995.

FAUlKneR, R.R. AND ANDERSON, A.B. "Short-Term Projects and Emergent Careers: Evidence from Hollywood.” American Journal of Sociology, Vol. 92 (1987), pp. 879-909.

Feller, W. An Introduction to Probability Theory and Its Applications: Volume I. New York: Wiley, 1950.

Grossman, G. and Helpman, E. "Incomplete Contracts and Industrial Organization." Mimeo, Department of Economics, Princeton University and Department of Economics, Harvard University, 1999.

Grossman, S.J. And Hart, O.D. "The Costs and Benefits of Ownership: A Theory of Lateral and Vertical Integration.” Journal of Political Economy, Vol. 94 (1986), pp. 691-719.

Gul, F. AND StAcChetTI, E. "The English Auction with Differentiated Commodities." Journal of Economic Theory, forthcoming.

Hart, O. And Moore, J. "Property Rights and the Nature of the Firm." Journal of Political Economy, Vol. 98 (1990), pp. 1119-1158.

Helper, S. AND LeVINE, D. "Long-Term Supplier Relations and Product-Market Structure.” Journal of Law, Economics and Organization, Vol. 8 (1992), pp. 561-581.

- MAcDuffie, J.P., AND SABEl, C. "The Boundaries of the Firm as a Design Problem." In M. Roe, ed., Corporate Governance Today. Oxford University Press, forthcoming.

Hendricks, K., Piccione, M., And Tan, G. "The Economics of Hubs: The Case of Monopoly." Review of Economic Studies, Vol. 62 (1995), pp. 83-99.

HenRIET, D. AND Moulin, H. "Traffic-Based Cost Allocation in a Network." RAND Journal of Economics, Vol. 27 (1996), pp. 332-345.

Holmström, B. And RoBerts, J. "The Boundaries of the Firm Revisited." Journal of Economic Perspectives, Vol. 12 (1998), pp. 73-94.

Holthausen, D.M. "Input Choices and Uncertain Demand." American Economic Review, Vol. 66 (1976), pp. 94-103. 
JaCKSON, M.O. And Wolinsky, A. "A Strategic Model of Social and Economic Networks." Journal of Economic Theory, Vol. 71 (1996), pp. 44-74.

Kranton, R. And Minehart, D. "A Theory of Buyer-Seller Networks." American Economic Review, forthcoming (a).

— AND — . "Competition for Goods in Buyer-Seller Networks." Review of Economic Design, forthcoming (b).

Lazerson, M. "Factory or Putting-Out? Knitting Networks in Modena." In G. Grabher, ed., The Embedded Firm: On the Socioeconomics of Industrial Networks. New York: Routledge, 1993.

Leland, H.E. "Theory of the Firm Facing Uncertain Demand.” American Economic Review, Vol. 62 (1972), pp. $278-291$.

LILIEN, D.M. "Sectoral Shifts and Cyclical Unemployment." Journal of Political Economy, Vol. 90 (1982), pp. 777-793.

LORENZ, E.H. "The Search for Flexibility: Subcontracting Networks in British and French Engineering." In P. Hirst and J. Zeitlin, eds., Reversing Industrial Decline?: Industrial Structure and Policy in Britain and Her Competitors. New York: St. Martin's Press, 1989.

MYerson, R. "Graphs and Cooperation in Games." Mathematics of Operations Research, Vol. 2 (1977), pp. $225-229$.

— . "Optimal Auction Design." Mathematics of Operations Research, Vol. 6 (1981), pp. 58-73.

NishigucHI, T. Strategic Industrial Sourcing: The Japanese Advantage. New York: Oxford University Press, 1994.

NoHria, N. "Information and Search in the Creation of New Business Ventures: The Case of the 128 Venture Group." In N. Nohria and R.G. Eccles, eds., Networks and Organizations: Structure, Form, and Action. Boston: Harvard Business School Press, 1992.

Piore, M.J. And Sabel, C.F. The Second Industrial Divide. New York: Basic Books, 1984.

Rabellotti, R. "Is There an 'Industrial District' Model? Footwear Districts in Italy and Mexico Compared." World Development, Vol. 23 (1995), pp. 29-41.

Rajan, R.G. AND Zingales, L. "Power in a Theory of the Firm." Quarterly Journal of Economics, Vol. 113 (1998), pp. 387-432.

Rogerson, W. "Contractual Solutions to the Hold-Up Problem.” Review of Economic Studies, Vol. 59 (1992), pp. 777-794.

Roth, A.E. AND Sotomayor, M.A.O. Two-Sided Matching: A Study in Game-Theoretic Modeling and Analysis. New York: Cambridge University Press, 1990.

RothSCHILD, M. AND WERDEN, G.J. "Returns to Scale from Random Factor Services: Existence and Scope." Bell Journal of Economics, Vol. 10 (1979), pp. 329-335.

Saxenian, A. Regional Advantage: Culture and Competition in Silicon Valley and Route 128. Cambridge, Mass.: Harvard University Press, 1994.

Schmitz, H. "Small Shoemakers and Fordist Giants: Tale of a Supercluster." World Development, Vol. 23 (1995), pp. 9-28.

SCHWERT, G.W. "Why Does Stock Market Volatility Change over Time." Journal of Finance, Vol. 44, (1989), pp. 1115-1153.

ScotT, A.J. Technopolis. Berkeley: University of California Press, 1987.

Segal, I. and Whinston, M. "Exclusive Contracts and Protection of Investments." Mimeo, Department of Economics, University of California at Berkeley and Department of Economics, Northwestern University, 1998.

Shapley, L.S. AND SHUBIK, M. "The Assignment Game I: the Core." International Journal of Game Theory, Vol. 1 (1972), pp. 111-130.

Smith, V.L., Backerman, S., and Rassenti, S. "Efficiency and Income Shares in High Demand Energy Networks." Mimeo, Department of Economics, University of Arizona, 1996.

STORPER, M. "The Transition to Flexible Specialisation in the U.S. Film Industry: External Economies, in the Division of Labour, and the Crossing of Industrial Divides." Cambridge Journal of Economics, Vol. 13 (1989), pp. 273-305.

TIROLE, J. "Incomplete Contracts: Where Do We Stand?" Econometrica, Vol. 67 (1999), pp. 741-781.

Uzzi, B. "The Sources and Consequences of Embeddness for the Economic Performance of Organizations: The Network Effect.” American Sociological Review, Vol. 61 (1996), pp. 674-698.

. "Social Structure and Competition in Interfirm Networks: The Paradox of Embeddedness." Administrative Science Quarterly, Vol. 42 (1997), pp. 35-97. 
Copyright of RAND Journal of Economics is the property of RAND Journal of Economics. The copyright in an individual article may be maintained by the author in certain cases. Content may not be copied or emailed to multiple sites or posted to a listserv without the copyright holder's express written permission. However, users may print, download, or email articles for individual use. 